\title{
Earth and Space Science
}

\section{RESEARCH ARTICLE 10.1029/2021EA001953 \\ Degradation at the InSight Landing Site, Homestead Hollow, Mars: Constraints From Rock Heights and Shapes}

Key Points:

- Rock heights and shapes at Homestead hollow indicate early transport of deflated ejecta sediments can account for infilling of the crater

- Near-rim rock heights and shapes relative to the expected original versus remnant ejecta thickness indicates $30 \mathrm{~cm}$ deflation at the current rim

- Exposure of later arriving, small ejecta rocks in the hollow supports very low estimates of degradation over most hollow history

Correspondence to:

J. A. Grant,

grantj@si.edu

Citation:

Grant, J. A., Wilson, S. A., Golombek, M., Trussell, A., Warner, N. H., Williams, N., et al. (2022). Degradation at the InSight landing site, Homestead hollow, Mars: Constraints from rock heights and shapes. Earth and Space Science, 9, e2021EA001953. https://doi. org/10.1029/2021EA001953

Received 7 AUG 2021

Accepted 24 DEC 2021

Author Contributions:

Formal analysis: J. A. Grant, S. A Wilson, M. Golombek, A. Trussell, N. Williams

Investigation: S. A. Wilson, N. H. Warner

Methodology: S. A. Wilson, M. Golombek, A. Trussell, N. Williams, H. Abarca, R. Deen

Resources: J. A. Grant

Software: H. Abarca

Writing - original draft: J. A. Grant, S. A. Wilson

(C) 2022 Smithsonian Institution and Jet Propulsion Laboratory. California Institute of Technology. Government sponsorship acknowledged. This article has been contributed to by US Government employees and their work is in the public domain in the USA. This is an open access article under the terms of the Creative Commons Attribution-NonCommercial License, which permits use, distribution and reproduction in any medium, provided the original work is properly cited and is not used for commercial purposes.

\author{
J. A. Grant ${ }^{1}$ (D) S. A. Wilson ${ }^{1}$ D, M. Golombek ${ }^{\text {ID }}$, A. Trussell ${ }^{2,3}$, N. H. Warner $^{4}$ (D, N. Williams ${ }^{2}$ (D), \\ C. M. Weitz ${ }^{5}$ D, H. Abarca ${ }^{2}$, and R. Deen ${ }^{2}$ (D) \\ ${ }^{1}$ Center for Earth and Planetary Studies, National Air and Space Museum, Smithsonian Institution, Washington, DC, USA, \\ ${ }^{2}$ Jet Propulsion Laboratory, California Institute of Technology, Pasadena, CA, USA, ${ }^{3}$ California Institute of Technology, \\ Pasadena, CA, USA, ${ }^{4}$ Department of Geological Sciences, SUNY Geneseo, Geneseo, NY, USA, ${ }^{5}$ Planetary Science Institute, \\ Tucson, AZ, USA
}

Abstract Rock shapes and heights around the InSight lander are examined to refine the degradation history of the $27 \mathrm{~m}$-diameter Homestead hollow. Results document decreasing average exposed rock height and increasing percentage of rocks where height comprises the short axis from outside to within the hollow and support prior models of ejecta deflation accompanied by hollow infilling. We estimate $0.3 \mathrm{~m}$ of deflation at the current rim that is realistic compared to rock relief, original ejecta thickness, and predicted aeolian contributions to infilling. We also find that shapes of embayed basalt rocks outside the hollow appear platy, bladed, and elongate in a triangular form factor plot, and more discoidal and bladed in an axes ratio plot. By contrast, expected shapes based on terrestrial studies of basalt rocks are mostly compact, compact platy, compact bladed, compact elongated, platy, bladed, and elongate in triangular form factor plots, and equant with lesser, but significant disc- and blade-shaped rocks in axes ratio plots. We find addition of $10 \mathrm{~cm}$ to the heights of rocks near the hollow rim, to account for continued partial embedding in ejecta, yields the best match between observed and expected rock shapes. Exposure of small ejecta rocks in the hollow supports degradation rates of $10^{-4} \mathrm{~m} / \mathrm{Myr}$ during most of hollow history. Results indicate that deflation from ejecta accompanied by downwind deposition in the hollow can account for the current degraded form of the crater. Our approach is a new tool for characterizing small crater degradation on regolith-covered lava plains on Mars.

\section{Introduction}

The InSight mission (Interior Exploration using Seismic Investigations, Geodesy, and Heat Transport) to Mars landed November 2018 in western Elysium Planitia at $4.502^{\circ} \mathrm{N}, 135.623^{\circ} \mathrm{E}$. InSight landed on a regolith-covered, Early Amazonian basaltic lava plain capped by $\sim 3 \mathrm{~m}$ of regolith formed and mixed by impact comminution of the underlying bedrock (Banerdt et al., 2020; Golombek, Warner et al., 2020; Golombek, Williams et al., 2020). The lander is within a highly degraded, 400-700 Myr old, quasi-circular, $27 \mathrm{~m}$-diameter, $0.3 \mathrm{~m}$ deep impact crater dubbed "Homestead hollow" (Golombek, Warner et al., 2020; Grant et al., 2020; Warner, Grant et al., 2020; Figure 1). Prior evaluation of thousands of craters around the lander in varying degradation states indicates the current 27 m-diameter hollow was enlarged by 10\%-20\% enlargement: it was originally 22-25 m-diameter and surrounded by a $0.7 \mathrm{~m}$ (locally up to $1 \mathrm{~m}$ ) high rim (Sweeney et al., 2018; Warner, Grant et al., 2020; Figure 2).

We favor a primary impact origin of Homestead hollow (rather than a secondary impact structure) for four reasons: (1) The seismic recording of hammering by the Heat Flow and Physical Properties Package (HP3) on InSight together with joint imaging, pressure, and seismic sensing of passing dust devils, indicates $\sim 3 \mathrm{~m}$ of aeolian and diffusional (mass wasting slope debris) infilling of the hollow interior (Banerdt et al., 2020; Golombek, Warner, et al., 2020). Given the present-day rim height of $0.3 \mathrm{~m}$, and an estimated pristine rim height of $0.7 \mathrm{~m}, \sim 3 \mathrm{~m}$ of infill yields a crater depth (d)-to-diameter(D) ratio of $0.15-0.17$, which exceeds the typical d $/ D$ of $\leq 0.1$ associated with secondary craters (e.g., Daubar et al., 2016; Pike \& Wilhelms, 1978), but matches that expected for primary impacts into unconsolidated material (Watters et al., 2017) and is the best fit to the measured $\mathrm{d} / D$ of all small, nearly pristine craters in the landing ellipse (Sweeney et al., 2018; Warner, Grant et al., 2020). (2) The pristine $\mathrm{d} / D$ of relatively fresh, similar-sized craters around the lander averages 0.15 , yielding a depth consistent with the inferred $\sim 3 \mathrm{~m}$ infilling, although this likely incorporates some secondary structures (Sweeney et al., 2018; Warner, Grant et al., 2020). (3) The degraded appearance of the hollow with its $0.3 \mathrm{~m}$-high rim implies that the pristine rim was higher, closer to the predicted 0.7 high 
Writing - review \& editing: $M$. Golombek, A. Trussell, N. H. Warner, C. M. Weitz rim (Sweeney et al., 2018; Warner, Grant et al., 2020). (4) The rim height of secondary craters is not well characterized, but younger, relatively pristine secondary craters associated with the Corinto impact crater have a d/D of 0.04-0.06 (Daubar et al., 2016; Golombek et al., 2017, 2018). The current $d / D$ of the hollow is 0.01 , its degraded appearance, and the estimated $\sim 3 \mathrm{~m}$ of infilling implies that the modification that has occurred is beyond what could have been accommodated by a shallow secondary crater. Nevertheless, the possibility that Homestead hollow is a secondary impact structure cannot be excluded.

Multiple lines of evidence indicate that the pristine ejecta deposit at Homestead Hollow was relatively wellmixed, with exponentially more small rocks than large rocks (e.g., Brown, 1989; Melosh, 1989; Schroder et al., 2020, 2021), and displayed relatively few large (>1 m) ejecta rocks relative to abundant sand-sized rocks (M. Golombek, Charalambous, et al., 2020; Golombek et al., 2018, 2021). First, prior work demonstrates that the relatively low energy impact that formed Homestead Hollow limited excavation to an impact gardened regolith "pre-processed" by 3 impact events (Charalambous et al., 2020; Golombek et al., 2018, 2021) that decreased the number of high velocity spalls and large rocks on/within the pristine ejecta (Head et al., 2002; Melosh, 1984). These multiple impacts would have produced abundant sand-sized material at the expense of fewer larger rocks (Golombek et al., 2018, 2021; M. Golombek, Charalambous et al., 2020). Hence, regardless of whether Homestead hollow formed as a primary or secondary impact structure, the entirety of its rim is comprised of ejecta and the underlying regolith with comparable properties.

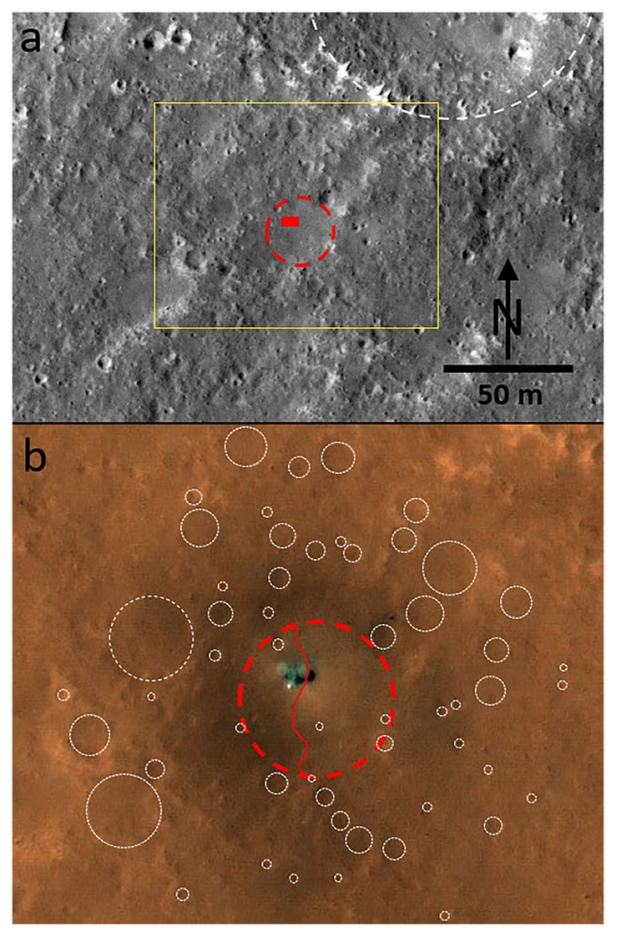

Figure 1. (a) The InSight lander (red box) in the quasi-circular $27 \mathrm{~m}$-diameter Homestead hollow degraded impact crater (red dashed circle) in western Elysium Planitia, Mars $\left(4.502^{\circ} \mathrm{N}, 135.623^{\circ} \mathrm{E}\right)$. The lander is $6 \mathrm{~m}$ measured across the solar panels, is in the northwestern quadrant of the hollow, and the lander workspace is to the south. Yellow box shows location of (b). Subframe of HiRISE color ESP_036761_1845 (0.25 m/pixel). (b) Color view of InSight lander in Homestead hollow (red dashed circle) and numerous other hollows (white dotted circles) in the immediate vicinity. Red line cutting across the hollow is the boundary between occurrence of relatively few rocks to the east versus $\sim 3 \mathrm{X}$ more rocks in the region to the west dubbed "Rocky Field" (see Figure 3). Landing rockets removed dust from the immediate surface and caused the bright zone and surrounding dark halo around the lander (Williams et al., 2019). Subframe of HiRISE color image ESP_061684_1845 $(0.25 \mathrm{~m} /$ pixel). Modified from Figure 1 in Grant et al. (2020).
Craters with boulder-sized rocks incorporated into their ejecta blankets, known as Rocky Ejecta Craters (or RECS), occur in the vicinity of the Insight lander and have diameters >40 m (Sweeney et al., 2018; Warner et al., 2017; Warner, Grant et al., 2020). The lack of meter-scale rocks indicates that smaller impacts, including the impact that formed Homestead Hollow, did not excavate below the regolith to fragment/eject larger rocks (Golombek et al., 2017). The latter is consistent with the limited number of meter-scale rocks measured on surfaces around the hollow and nearby $<30-40$ m craters using lander and orbital images (Golombek et al., 2021; Golombek, Williams et al., 2020; Warner et al., 2017) and 3-10 meters of impact fragmented regolith in the vicinity of the hollow. Hence, the pristine properties of the ejecta/ rim around the hollow were well-mixed and not capped by numerous large (spall) rocks such as those that occur around much larger craters in more energetic, regolith-free impact settings on the Moon and Mars (Krishna \& Kumar, 2016; Lakshmi \& Kumar, 2020).

Rocks at InSight are basaltic in composition and likely of volcanic lava origin based on: (1) the relative proximity to north-south trending wrinkle ridges (Golombek et al., 2018); (2) the presence of degraded lobate flow margins in the region (Golombek et al., 2018); (3) occurrence of platy and ridged surface textures and possible lava inflation plateaus and volcanic vents (Pan et al., 2020); (4) Rocks with a fairly uniform fine-grained aphanitic texture (Golombek, Warner et al., 2020); (5) The absence of any observable sedimentary structures in rocks at the landing site; and (6) evidence that the regional Hesperian transition unit around the lander (Tanaka et al., 2014) experienced an Early Amazonian-aged resurfacing event linked to regionally occurring volcanism (Warner et al., 2017).

Prior studies concluded that hollow degradation was dominated by aeolian and mass wasting processes with lesser impact contributions that stripped and lowered the near-rim and ejecta, resulting in nearly complete infilling of the crater interior and burial of any rocks lining the hollow (Golombek, Warner et al., 2020; Grant et al., 2020; Warner, Grant, et al., 2020). These studies concluded that degradation of the hollow during the first 0.05-0.1 Ga after formation was relatively more rapid and dominated by deflation of fines from the ejecta, some of which were transported downwind and infilled the crater, and was accompanied by mass-wasting along the crater wall. The deg- 
A

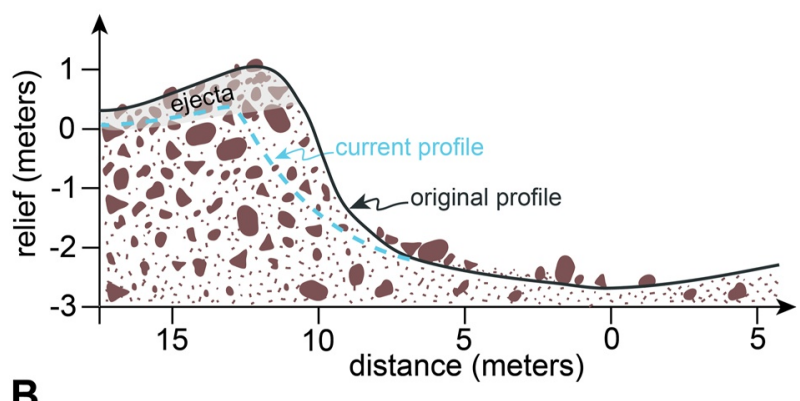

B

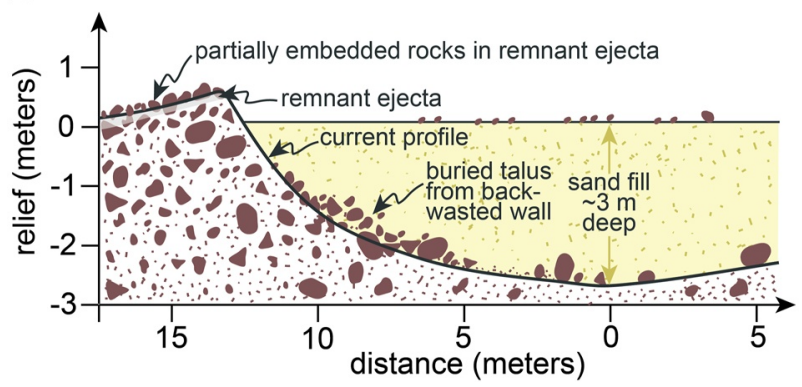

Figure 2. Schematic cross-section through the original (a) and current (b) Homestead hollow. As described in the text, the cross-sections are based on the assumption that the hollow is a primary impact structure. The crater formed into a pre-existing regolith characterized by few large rocks and abundant sand-sized fines (M. Golombek, Charalambous et al., 2020; Golombek et al., 2018, 2021; Golombek et al., 2018). The original diameter of 22-25 m was surrounded by a $0.7 \mathrm{~m}$-high rim (Sweeney et al., 2018; Warner, Grant, et al., 2020) of well-mixed, unconsolidated regolith M. Golombek, Charalambous, et al., 2020; Golombek et al., 2018, 2021) and overlying ejecta capped by few high velocity spalls/large rocks (Head et al., 2002; Melosh, 1984). Aeolian deflation of the bulk of the ejecta and downwind infilling of the crater accompanied by early mass-wasting and talus accumulation resulted in the present muted expression of the hollow. If the hollow was formed by a secondary impact, the depth would have been less and the structure would have been surrounded by a lower rim of the same unconsolidated material. radation continued until coarser rocks created a surface lag on the ejecta and (or) sufficient relief around partially exposed rocks created a boundary layer that precluded further stripping while accumulating aeolian fill stabilized the walls of the hollow (Grant et al., 2020; Warner, Grant, et al., 2020). Comparisons made using orbital data covering nearby, similar-sized craters in varying stages of degradation (Sweeney et al., 2018; Warner, Grant, et al., 2020) revealed that Homestead hollow assumed something close to its present form within the first 0.05-0.1 Ga after formation (Grant et al., 2020; Warner, Grant, et al., 2020).

The interior of the hollow is characterized by relatively fewer and smaller rocks with respect to the margin and near-rim of the exterior (Figure 3), and there are $\sim 3 \mathrm{X}$ more rocks in an area dubbed "Rocky Field" on the western interior floor relative to the eastern interior floor (Figures 1 and 3). The rocks capping the hollow fill were previously interpreted to be ejecta rocks delivered during nearby, later impact events (Grant et al., 2020; Warner, Grant, et al., 2020), and are therefore not associated with hollow formation: their continued partial exposure highlights evidence cited in prior studies for minimal modification that occurred over most of the history of the hollow (Grant et al., 2020; Warner, Grant, et al., 2020).

The cumulative result of hollow degradation is characterized primarily by an increase in the number and relative relief of rocks visible along the margin and exterior of the hollow relative to the filled interior (Figures 2 and 3), and there is no significant topographic transition between the two areas (Warner, Grant, et al., 2020). Nevertheless, the relative relief and shapes of rocks in and around the hollow has not been quantified, and thus possible implications for the amount of exterior stripping and accompanying infilling relative to mass wasting or direct infilling by ejecta arriving during later impacts is not well understood.

Rock height (vertical measurement of the rock above the adjacent local surface) and three-dimensional shape (various comparisons between the short, intermediate, and long axes of a rock) can help assess the varying amount, intensity, and number of geomorphic processes affecting a landscape over time. Specifically, height and shape can help identify where erosion dominates over burial and (or) help to identify locales where new materials may have been introduced as infilling deposits (Figures 2 and 3).

A number of studies have examined the two- and three-dimensional shapes of rocks (i.e., using either two or three of the principal axes of a rock) on the Earth and Mars. Two-dimensional rock shape characterization, focusing on properties including sphericity (Corey, 1949) and angularity (Krumbein, 1941), has been applied to rocks on Mars where information on all three principal rocks axes is precluded by lack of accurate depth or height information (e.g., Garvin et al., 1981; Yingst et al., 2007, 2008, 2010, 2013; Craddock \& Golombek, 2016). Three-dimensional evaluation of rock shapes requires accurate measure of all dimensions and can include various ratios or relations between the long, intermediate, and short axes of a rock (e.g., Zingg, 1935; Sneed \& Folk, 1958). These relationships are used to characterize rocks as more rounded (compact or equant), disc-shaped, bladed, or elongate/rod-shaped (Figure 4). As general examples, Graham \& Midgley (2000) showed that three-dimensional rock form is a discriminator between scree, moraine, and frost-shattered deposits. Three-dimensional shape characteristics for terrestrial basalt rocks in a wide range of geologic and weathering environments, including impact, however, show little variability over a range of sizes (e.g., Craddock \& Golombek, 2016; Ehlmann et al., 2008; Kumar et al., 2014), interpreted to reflect control by cooling fractures on how the rocks break (Craddock \& Golombek, 2016). Three-dimensional information related to rock axes at InSight (in the near field to a range of $15 \mathrm{~m}$ ) is available via processing of stereo images acquired by the lander, enabling direct comparison of rock shapes on Mars to those associated with basalt rocks on the Earth. 

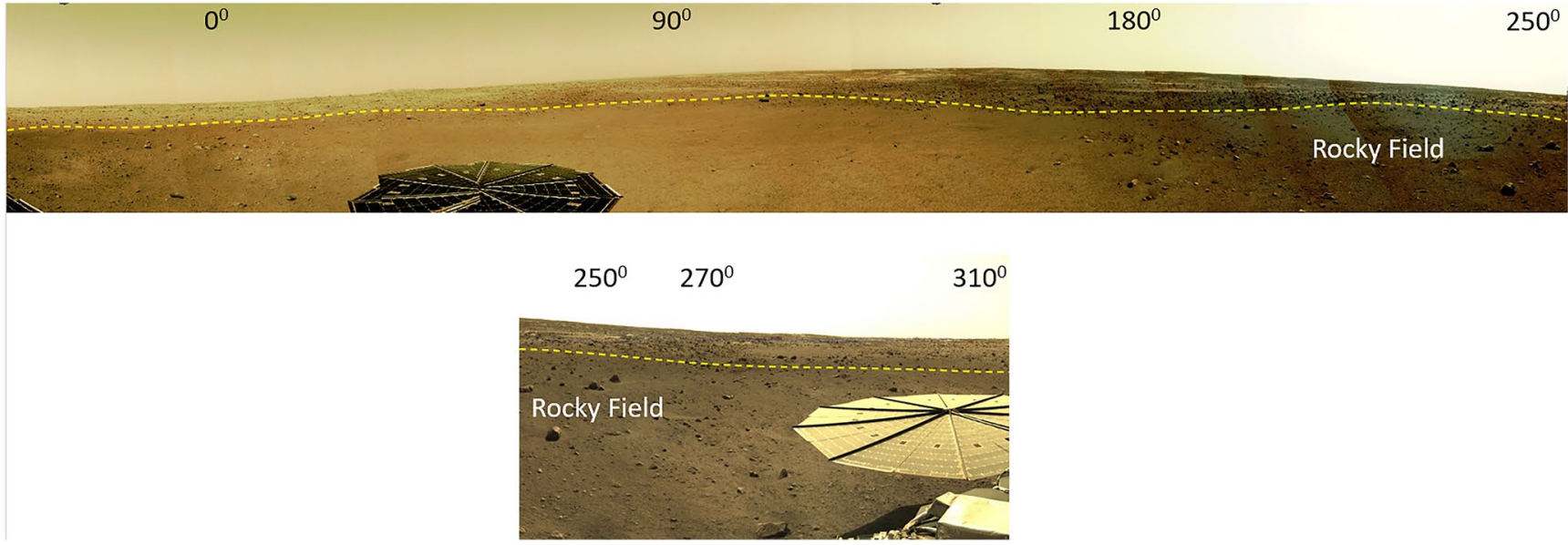

Figure 3. Mosaic covering approximately $290^{\circ}$ around the north, east and south side of lander in Homestead hollow (top) and mosaic covering approximately $70^{\circ}$ around the west side of the lander (bottom). Total coverage when including for overlap between the two mosaics is approximately $335^{\circ}$. Near- and mid-field coverage in the mosaics (out to $\sim 15 \mathrm{~m}$ from the lander) matches that shown in the orthomosaic in Figure 5 and enabled measurement of rocks larger than 1 and 3 within $10 \mathrm{~m}$ of the lander across a broad swath of the hollow interior, within $\sim 1 \mathrm{~m}$ of the margin (yellow dashed line) to the west and north side of the hollow, and on the northwest exterior near-rim within a few meters of the current hollow rim. For scale, the lander solar panels in both mosaics are $2.15 \mathrm{~m}$ in diameter. Rocky Field denotes the $\sim 3 X$ higher density of rocks on the west-northwest part of the hollow interior. Numbers refer to azimuth where $0^{\circ}$ is true north. Mosaic D_LRGB_0014_ RAS030100CYL_R_SCIPANQM1 (a) and IDC Mosaic D_LRGB_0119_RAD030100CYL_R_AUTOGENM3 (b). Small black areas around mosaic margins are gores in the image data.

We analyze variations in the height and shape of basalt rocks around the InSight lander to provide new constraints on degradation processes active at the landing site over time to further constrain the responsible processes, their timing, and importance. For example, variations in rock height together with information of degradation processes can quantify differences in relief from outside to within the hollow that relates to regions of net erosion versus deposition. Moreover, the relief of rock rocks in ejecta around the hollow, where stripping has dominated (Grant et al., 2020; Warner, Grant et al., 2020), can be equated to the amount of surface lowering that has occurred when compared to expectations of the original ejecta thickness and character of the deposit (e.g., few large rocks and abundant sand-sized, see Golombek et al., 2018; M. Golombek, Charalambous et al., 2020; Golombek et al., 2021). We assume that there should not be significant differences in three-dimensional rock

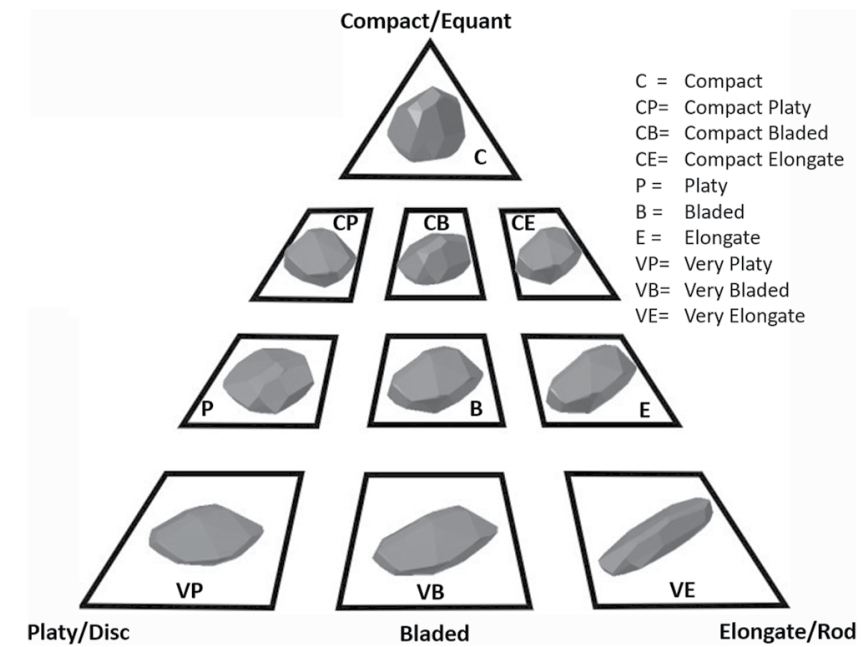

Figure 4. Schematic rock shape classification diagram based on the relative lengths of orthogonal axes (modified from Figure 1c in Bonneau et al., 2019). Rock axes measured in the InSight landing site are plotted to evaluate shapes in (interior), around (margin), and outside (exterior) of Homestead hollow (see Figure 7). shapes at InSight relative to the generally similar shapes of basalt rocks that are known to occur in a range of terrestrial environments (e.g., Craddock \& Golombek, 2016; Ehlmann et al., 2008; Kumar et al., 2014) and examine how any apparent differences in shape may relate to their partial burial/ incomplete exhumation as a result of hollow degradation. For example, the observed versus expected form of the basalt rocks outside the hollow is compared with rock relief and expectations of the pristine ejecta thickness. Our goal is to predict the degree to which rocks remain embedded in the regolith versus being fully exposed on the surface and relate that to the amount of stripping that has occurred around the hollow. Further, to minimize potential uncertainties related to setting, we emphasize comparison of rock shape parameters for the basalt rocks in ejecta at Homestead hollow to rock shape parameters for basalt rocks in the ejecta deposit at the simple impact structure Lonar crater, in India (Kumar et al., 2014). Although the hollow is $27 \mathrm{~m}$ across relative to the $1.2 \mathrm{~km}$-diameter Lonar crater, fragmentation processes associated with impacts at a wide range in scales produce rock distributions with exponentially more small rocks than large rocks (e.g., Brown, 1989; M. Golombek, Charalambous et al., 2020; Golombek et al., 2018, 2021; Melosh, 1989; Schroder et al., 2020, 2021. Our approach helps detail where and how much degradation occurred at the InSight landing site, and whether processes occurring locally around and within the hollow can account for the current degraded appearance or whether additional sediments from more 

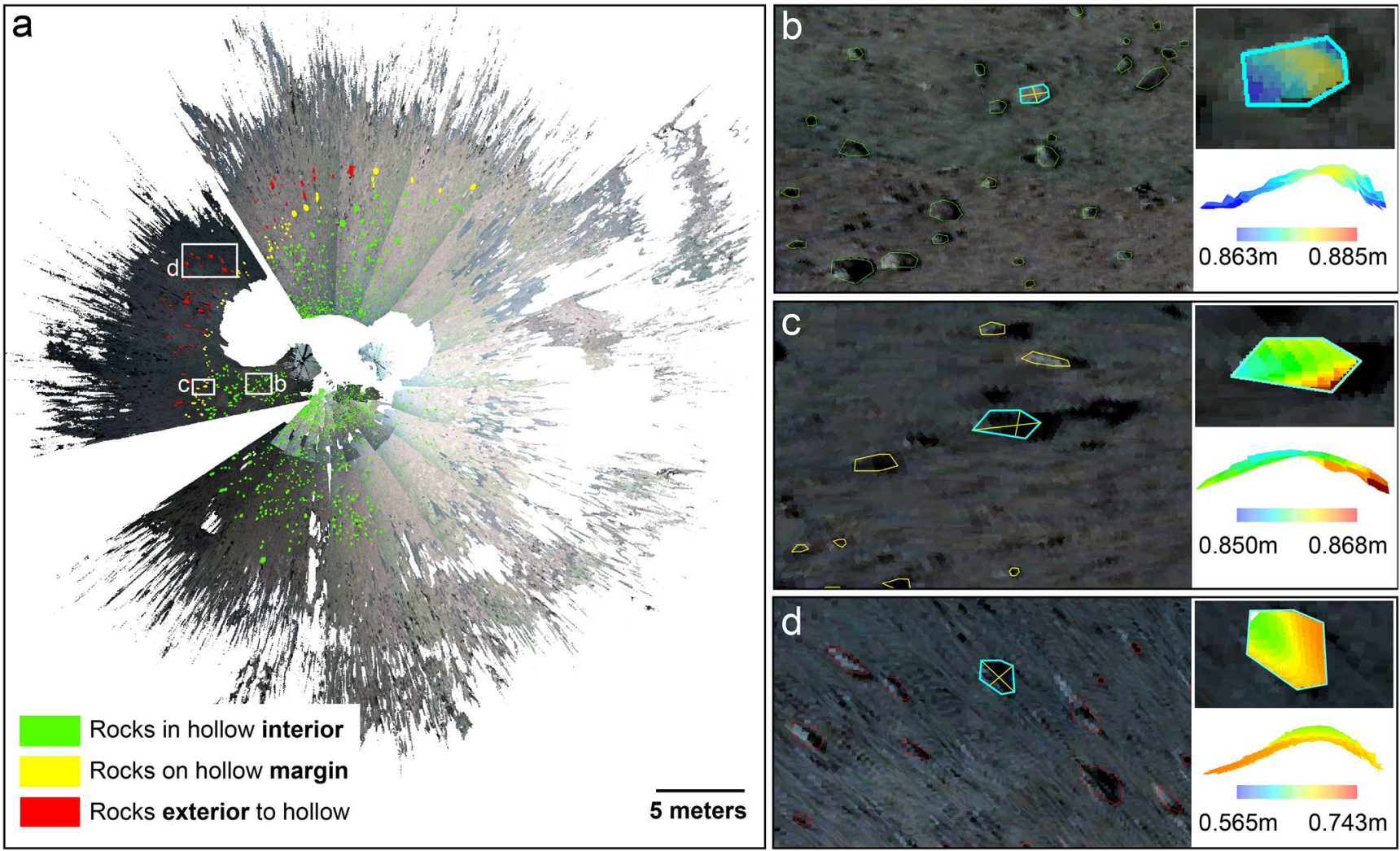

Figure 5. (a) Image of the Instrument Deployment Camera (IDC) orthomosaic coverage in and around Homestead hollow that matches the same area visible in the near- and mid-fields in Figure 3. White gores are gaps in the data coverage. The current study focuses on rocks within $10 \mathrm{~m}$ of the lander and includes rocks across a broad swath of the hollow interior (green), within $\sim 1 \mathrm{~m}$ of the margin to the west of the north side of the hollow (yellow, see Figure 3), and outside of the hollow within a few meters of rim to the west and north of the lander (red, see Figure 3). Rocks mapped on the orthomosaic by Golombek et al. (2021). (b) Rocks on floor of the hollow (outlined in green) with rock fragment (FID 1450) outlined in blue, which is highlighted to show the shortest $(0.055 \mathrm{~m})$ and longest (0.097 m) axes (yellow lines). Subset of the orthomosaic is $1.3 \mathrm{~m}$ across. Inset shows the elevation data of the highlighted rock fragment (height above the surface is $0.01 \mathrm{~m}$ ) and shape of the rock from the digital elevation model (DEM). (c) Rocks on the margin of the hollow (outlined in yellow). Rock fragment (FID 1562, outlined in blue) has a short and long axis of 0.079 and $0.201 \mathrm{~m}$, respectively (yellow lines). Subset of the orthomosaic is $1.25 \mathrm{~m}$ across. Inset shows the elevation data of the highlighted rock fragment (height above the surface is $0.01 \mathrm{~m}$ ) and shape of the rock from the DEM. (d) Rocks exterior to the hollow (outlined in red). Rock fragment (FID 1718, outlined in blue) has a short and long axis of 0.2 and $0.31 \mathrm{~m}$, respectively (yellow lines). Subset of the orthomosaic is $\sim 3 \mathrm{~m}$ across. Inset shows the elevation data of the highlighted rock fragment (height above the surface is $0.15 \mathrm{~m}$ ) and shape of the rock from the DEM. North is toward the top in all images.

distant sources are also required. The approach provides a template that can be used to constrain degradation occurring on widespread, broadly similar volcanic surfaces (e.g., Grant et al., 2004, 2020; Tanaka et al., 2014; Warner, Schuyler, et al., 2020) emplaced over latter portions (e.g., Amazonian) of Mars history.

\section{Measuring Rock Dimensions}

Panorama DEM and Orthomosaic: The orthogonal dimensions (shortest horizontal, longest horizontal, and maximum vertical height) of rocks around the InSight lander were measured from a panorama digital elevation model (DEM) and orthomosaic that covers most of the terrain surrounding the lander to a range of $\sim 15 \mathrm{~m}$ (Figure 5). The panorama DEM and orthoimage were created by mosaicking 283 stereo images acquired by InSight's arm-mounted Instrument Deployment Camera (IDC, Figure 3) (angular resolution of $0.82 \mathrm{mrad} / \mathrm{pixel}$ at the center of the image, see Maki et al., 2018). As summarized in Golombek et al. (2021), the scale of the IDC images varies from $0.12 \mathrm{~cm} /$ pixel to $2.8 \mathrm{~cm} /$ pixel with increasing range from the lander, and the DEM has elevation postings every $5 \mathrm{~mm}$. The panorama orthomosaic was bundle adjusted (Abarca et al., 2019), except for the western region, which is separated from the rest of the panorama (Figures 3 and 5). Error in stereo coordinates is the result of uncertainty in the robotic arm position and stereo processing errors. Pre-launch tests of the surface in front of the lander had a mean horizontal accuracy of $11 \mathrm{~mm}$, a mean absolute vertical accuracy of $6.5 \mathrm{~mm}$, and mean relative vertical 
accuracy of $5 \mathrm{~mm}$. After landing, 56 images taken in front of the lander on sol 12 had a spatial accuracy between adjacent stereo frames of $1.9 \mathrm{~mm}$ overall with a maximum error of $4 \mathrm{~mm}$ between frames. Images further from the lander, including horizon images, were bundle adjusted to those close to the lander. The error within each stereo pair is characterized by the stereo range error of the IDC camera (Maki et al., 2018), and range error in the DEM increases from $<1 \mathrm{~cm}$ at the edge of the coverage closest to the lander to $\sim 13 \mathrm{~cm}$ at a distance of $10 \mathrm{~m}$ from the lander. Spatial uncertainties in the orthomosaic of $<4 \mathrm{~mm}$ in the workspace (area south of the lander that can be reached by the lander arm to place instruments, generally within a few meters of the lander) to $<1 \mathrm{~cm}$ at $10 \mathrm{~m}$ distance from the lander, yet uncertainties in the measurements of rocks over small distances within the orthomosaic are much less, and do not have an appreciable effect on derived rock sizes. Golombek et al. (2021) further estimated that the IDC pixel-scale is $0.5 \mathrm{~cm}$ at $5 \mathrm{~m}$ distance and that most of the rocks in the DEM down to $0.03 \mathrm{~m}$ diameter could be counted out to $10 \mathrm{~m}$ We include rocks larger than $1 \mathrm{~cm}$ in our calculations of rock height, but also calculate all rock parameters using only rocks larger than $3 \mathrm{~cm}$ to understand any potential measurement errors related to decreasing resolution and occlusion of small rocks at increasing range and ensure consistency between rock sizes examined in the hollow and closer to the lander versus rock sizes on the exterior near rim and farther from the lander. Golombek et al. (2021) noted the effects of decreasing resolution and occlusion and showed that their focus on rocks larger than $3 \mathrm{~cm}$ enabled accurate definition of the size-frequency distribution. Our focus on rock size and shape rather than size-frequency lessens the importance of decreasing resolution and occlusion on our results. Moreover, the IDC is at or very close to $1.25 \mathrm{~m}$ above the surface for panorama images (varies slightly due to articulation required for pointing), the small increase in elevation towards and outside of the rim, and the $10 \mathrm{~m}$ range limit of our measurements imply the number of undercounted rocks due to these effects is small.

Methods: We collected information on a population of 2,034 rocks with a short axis $>1 \mathrm{~cm}$ mapped by Golombek et al. (2021) whose dimensions were measured by digitizing polygonal outlines (using a maximum vertex spacing of $0.0045 \mathrm{~m}$ ) of visible rocks in the orthomosaic in ArcGIS (Golombek et al., 2021). We further culled all rocks with a short axis smaller than $3 \mathrm{~cm}$ from this population to ensure consideration of a separate population of uniform minimum rock size at all ranges considered. These populations of rocks within $10 \mathrm{~m}$ of the lander cover about half of the hollow interior, and one quarter of the hollow margin and exterior (nearest few meters beyond the rim) to the west-north which we believe allows reliably characterizing their size and shape (Figure 5).

A convex hull, which is the smallest convex polygon enclosing the rock (representing the minimum bounding geometry), was calculated to provide the shortest and longest axes for each (Golombek et al., 2021). The longest axis is calculated as the longest distance between any 2 vertices of the minimum bounding polygon, and the shortest axis is the shortest distance between any two vertices of the minimum bounding polygon measured orthogonal to the longest axis. These measurements represent horizontal dimensions with no elevation information, yielding the small and large axes for each rock fragment. To assess the maximum height of each rock, we started with the same data set of 2,034 rocks noted above (Golombek et al., 2021), but removed 31 rocks that were not entirely covered by the $5 \mathrm{~mm}$ DEM. The height $(Z$ ) of each rock was derived from the $5 \mathrm{~mm}$ DEM (with estimated vertical precisions better than $1 \mathrm{~mm}$ based on $10 \%-20 \%$ of the spatial elevation posting scale) using the Add Surface Information analyst tool in ArcGIS, which calculated the difference between the maximum (Z_MAX) and minimum (Z_MIN) values for each rock (as mapped by the bounding polygon from Golombek et al., (2021)). Measurements are rounded to the nearest centimeter to avoid false precision in the estimated dimensions.

Our final database of rock dimensions includes 2,003 rocks larger than $1 \mathrm{~cm}$ and 654 rocks larger than $3 \mathrm{~cm}$ (Figure 5, see Data Repository, Grant et al., 2021), distributed in three areas (Table 1): A) the hollow interior ( $n>1 \mathrm{~cm}=1,850, n>3 \mathrm{~cm}=504$, including Rocky Field and more rock-free portions of the interior); B) the hollow margin $(n>1 \mathrm{~cm}=68, n>3 \mathrm{~cm}=65)$ defined as rocks within $1 \mathrm{~m}$ of the zone of increased rock density relative to the hollow interior that occurs at variable range from the hollow center due to imperfections in its circular outline Figure 3); and C) the hollow exterior $(n>1 \mathrm{~cm}=85, n>3 \mathrm{~cm}=85)$ as defined by up to three meters beyond the hollow margin to the west-northwest of the lander. Although the DEM does not cover all portions of the hollow and has varying coverage beyond the rim (due to the lander being located towards the NW corner of the hollow and resolution of the IDC images as noted) it does include well over half of the interior and approximately one quarter of the margin and exterior. Moreover, qualitative review of the changing rock distribution around and outside the hollow in IDC images (see Figure 3) leads us to conclude the DEM coverage is representative. Rock dimensions (shortest horizontal, longest horizontal, and maximum height) were used to characterize 
Table 1

Measured Parameters for the Homestead Hollow Exterior (and Exterior $+10 \mathrm{~cm}$ Height), Margin, and Interior, With Comparison to Lonar Crater

\begin{tabular}{|c|c|c|c|c|c|}
\hline Location/Parameter & Exterior & Margin & Interior & Lonar crater & Exterior $+10 \mathrm{~cm}$ height \\
\hline Number of all rocks & 85 & 68 & 1,850 & $\mathrm{n} / \mathrm{a}$ & $\mathrm{n} / \mathrm{a}$ \\
\hline Average height all rocks & $6 \mathrm{~cm}$ & $4 \mathrm{~cm}$ & $1 \mathrm{~cm}$ & $\mathrm{n} / \mathrm{a}$ & $\mathrm{n} / \mathrm{a}$ \\
\hline Average height std. Dev. All rocks & 0.089 & 0.079 & 0.02 & $\mathrm{n} / \mathrm{a}$ & $\mathrm{n} / \mathrm{a}$ \\
\hline 10 Tallest rocks & $23-30 \mathrm{~cm}$ & $4-33 \mathrm{~cm}$ & $14-26$ & $\mathrm{n} / \mathrm{a}$ & $\mathrm{n} / \mathrm{a}$ \\
\hline$\%>10 \mathrm{~cm}$ tall & $22 \%$ & $10 \%$ & $1 \%$ & $\mathrm{n} / \mathrm{a}$ & $\mathrm{n} / \mathrm{a}$ \\
\hline$\%$ Height $=$ short axis & $78 \%$ & $91 \%$ & $97 \%$ & $\mathrm{n} / \mathrm{a}$ & $\mathrm{n} / \mathrm{a}$ \\
\hline Normalized height & 0.42 & 0.27 & 0.25 & $\mathrm{n} / \mathrm{a}$ & $\mathrm{n} / \mathrm{a}$ \\
\hline Normalized height std. Dev. & 0.65 & 0.34 & 0.42 & $\mathrm{n} / \mathrm{a}$ & $\mathrm{n} / \mathrm{a}$ \\
\hline Number of rocks $>3 \mathrm{~cm}$ & 85 & 65 & 504 & $\mathrm{n} / \mathrm{a}$ & $\mathrm{n} / \mathrm{a}$ \\
\hline Average height rocks $>3 \mathrm{~cm}$ & $6 \mathrm{~cm}$ & $4 \mathrm{~cm}$ & $2 \mathrm{~cm}$ & $\mathrm{n} / \mathrm{a}$ & $\mathrm{n} / \mathrm{a}$ \\
\hline Average height std. Dev. $>3 \mathrm{~cm}$ rocks & 0.089 & 0.081 & 0.033 & $\mathrm{n} / \mathrm{a}$ & $\mathrm{n} / \mathrm{a}$ \\
\hline 10 Tallest rocks $>3 \mathrm{~cm}$ & $23-30 \mathrm{~cm}$ & $4-33 \mathrm{~cm}$ & $14-26$ & $\mathrm{n} / \mathrm{a}$ & $\mathrm{n} / \mathrm{a}$ \\
\hline$\%>10 \mathrm{~cm}$ tall $>3 \mathrm{~cm}$ & $22 \%$ & $10 \%$ & $3 \%$ & $\mathrm{n} / \mathrm{a}$ & $\mathrm{n} / \mathrm{a}$ \\
\hline$\%$ Height $=$ short axis $>3 \mathrm{~cm}$ & $78 \%$ & $89 \%$ & $97 \%$ & $\mathrm{n} / \mathrm{a}$ & $\mathrm{n} / \mathrm{a}$ \\
\hline Normalized height $>3 \mathrm{~cm}$ & 0.42 & 0.27 & 0.27 & $\mathrm{n} / \mathrm{a}$ & $\mathrm{n} / \mathrm{a}$ \\
\hline Normalized height std. Dev. $>3 \mathrm{~cm}$ & 0.65 & 0.35 & 0.35 & $\mathrm{n} / \mathrm{a}$ & $\mathrm{n} / \mathrm{a}$ \\
\hline Max proj. sphericity average & 0.35 & 0.33 & $\mathrm{n} / \mathrm{a}$ & 0.72 & 0.65 \\
\hline Max proj. sphericity range & $0.11-0.87$ & $0.10-0.81$ & $\mathrm{n} / \mathrm{a}$ & $0.11-1.0$ & $0.29-0.85$ \\
\hline Dev. compactness average & 0.18 & 0.16 & $\mathrm{n} / \mathrm{a}$ & 0.53 & 0.45 \\
\hline Dev. compactness range & $0.02-0.74$ & $0.02-0.73$ & $\mathrm{n} / \mathrm{a}$ & $0.18-1.0$ & $0.11-0.68$ \\
\hline Form factor average & 0.57 & 0.52 & $\mathrm{n} / \mathrm{a}$ & 0.56 & 0.49 \\
\hline Form factor range & $0.18-0.97$ & $0.05-0.90$ & $\mathrm{n} / \mathrm{a}$ & $0.0-1.0$ & $0.01-0.95$ \\
\hline
\end{tabular}

and evaluate any systematic changes in rock height or shape within the hollow interior, along the hollow margin, or exterior to the hollow. Our initial assumption is that the rock sizes lining the interior and along the margin and exterior should all be generally similar in size distribution given that they are excavated from a regolith pre-mixed by previous impacts. By contrast, some craters whose excavation is not confined to impact regolith can display smaller rocks along their interior (e.g (Krishna \& Kumar, 2016; Lakshmi \& Kumar, 2020). Because impact craters increase in depth towards the center and because the hollow fill has a nearly flat expression, we expect rocks to be increasingly buried by increasing thickness of fill from the margin towards the center of the hollow.

\section{Measuring Rock Shape}

Rock shapes in and around the Homestead hollow were derived using commonly used calculations (Sneed \& Folk, 1958) for maximum projection sphericity $(\varphi)$, deviation from compactness $(D)$, and form factor $(F)$ :

$$
\begin{gathered}
\varphi=\sqrt[3]{\frac{S^{2}}{L I}} \\
D=\frac{S}{L} \\
F=\frac{L-I}{L-S}
\end{gathered}
$$

where $L, I$, and $S$ correspond to the long, intermediate, and short axes of each rock, respectively. Ratios of the length of each axis are then plotted to obtain the form factor using the Equations 1-3 in the TRI-PLOT excel pro- 
gram published by Graham \& Midgley (2000) to constrain the distribution of compact, platy, bladed, and elongate rocks (Figure 4). In addition, the ratios of the rock intermediate to long axis versus rock short to intermediate axis was plotted separately (after Zingg, 1935) to characterize whether rocks are more equant, discoidal, bladed, or rod-shaped relative to expectations from studies of terrestrial basalt rocks (e.g., Craddock and Golombek, 2016; Ehlmann et al., 2008; Kumar et al., 2014).

\section{Results}

Rock heights on the exterior, margin, and interior of the hollow (Figures 5 and 6) are often the shortest measured axis in both the $>1 \mathrm{~cm}$ and $>3 \mathrm{~cm}$ rock populations (height is the short axis for $78 \%$ of exterior rocks in both populations, $91 \%$ and $89 \%$ of margin rocks in the $>1 \mathrm{~cm}$ and $>3 \mathrm{~cm}$ populations, respectively, and $97 \%$ of interior rocks in both populations) (Table 1, see also Data Repository, Grant et al. (2021)). For the exterior of the hollow, the 10 tallest rocks stand between $23-30 \mathrm{~cm}$ in exposed relief (five largest rocks are $>28 \mathrm{~cm}$ in height), and $22 \%$ of the rocks are $>10 \mathrm{~cm}$ tall in both populations. The 10 tallest rocks along the hollow margin stand between $4-33 \mathrm{~cm}$ in exposed relief (five largest rocks are $25-34 \mathrm{~cm}$ in height), with $10 \%$ of the rocks $>10 \mathrm{~cm}$ tall in both populations. In the hollow interior, the 10 tallest rocks stand between $14-26 \mathrm{~cm}$ in exposed relief, but only $1 \%$ and $3 \%$ of the rocks $>1 \mathrm{~cm}$ and $>3 \mathrm{~cm}$ populations are $>10 \mathrm{~cm}$ tall, respectively (Table 1). The decrease in rock height from the exterior to the interior of the hollow is also apparent in the statistical mean height and standard deviation of rocks within each zone, with rocks $>1 \mathrm{~cm}$ from outside the hollow, around the hollow margin, and within the hollow measuring $6 \pm 0.089,4 \pm 0.079$, and $1 \pm 0.020 \mathrm{~cm}$ tall, respectively (Table 1, Figure 6a). The same trend in decreasing rock height is observed in the $>3 \mathrm{~cm}$ population, with rocks outside, around (margin), and within the hollow measuring $6 \pm 0.089,4 \pm 0.081$, and $2 \pm 0.033 \mathrm{~cm}$ tall, respectively (Table 1, Figure 6b). The standard deviation and minimal to non-existent overlap in standard error (e.g., between the exterior and interior rocks) for the rock height in each zone indicates that the differences are significant (Figures 6a and $6 \mathrm{~b}$ ), especially between the exterior and the interior of the hollow in both populations. To evaluate whether the decreasing height of rocks from outside to within the hollow is due to increased exposure outside and greater burial inside the hollow versus occurrence of larger rocks (with greater relief) outside and smaller rocks inside, we normalized height values for both populations by dividing the rock height by the average of the width and length (or diameter). Resultant $>1 \mathrm{~cm}$ values for the exterior rocks are 0.42 ( 0.65 standard deviation) versus 0.27 ( 0.34 standard deviation) and 0.25 ( 0.42 standard deviation) for the margin and interior rocks, respectively. The normalized $>3 \mathrm{~cm}$ values are similar and are 0.42 ( 0.65 standard deviation), 0.27 ( 0.35 standard deviation), and 0.27 ( 0.35 standard deviation) for the exterior, margin, and interior, respectively.

Our study of rock shapes on the exterior and margin of the hollow (see also Grant et al. (2021) Data Repository) focuses on constraining the amount of deflation that has occurred there. We use the $>1 \mathrm{~cm}$ population for shape analysis, but note there is minimal difference between the $>1 \mathrm{~cm}$ and $>3 \mathrm{~cm}$ populations on the exterior and margin (Table 1) and expect that size will not influence shape based on prior work on basalt rock shape in terrestrial settings (Craddock \& Golombek, 2016; Ehlmann et al., 2008; Kumar et al., 2014). For exterior rocks, the maximum projection sphericity (Equation 1) ranges from 0.11 to 0.87 (compact to very elongate) with a mean of 0.35 ( 0.21 standard deviation) and from 0.10 to 0.81 (compact to very elongate) with a mean of 0.33 ( 0.15 standard deviation) for the margin (Table 1). The deviation from compactness (Equation 2) is 0.02-0.74 (very platy to barely into the compact field) with a mean of 0.18 ( 0.18 standard deviation) for the exterior and from 0.02 to 0.73 (very platy to barely into the compact field) with a mean of 0.16 ( 0.13 standard deviation) for the margin (Table 1). The form factor (Equation 3) for the exterior ranges from 0.18 to 0.97 (very platy to very elongate) with a mean of 0.57 ( 0.18 standard deviation) for the exterior and from 0.05 to 0.90 (very platy to very elongate) with a mean of 0.52 ( 0.17 standard deviation) for the margin (Table 1). By comparison, basalt rock in the ejecta deposit at Lonar crater have a maximum projection sphericity $0.11-1.0$ with a mean of 0.72 , the deviation from compactness is $0.18-1.0$ with a mean of 0.53 , and the form factor ranges from 0 to 1 with a mean of 0.56 (Table 1). As such, the most similar shape parameter between the rocks at InSight and in the ejecta at Lonar crater is the form factor. When plotted (Sneed \& Folk, 1958; Zingg, 1935) and compared to the shape of basaltic rocks in ejecta at Lonar crater (Kumar et al., 2014), however, we note large differences (Figures 7 and 8): the rocks in all three zones in and around the hollow at InSight are more platy, bladed, and elongate in the triangular form factor plot (Figure 7) and the bulk of rocks inside the hollow are discoidal and bladed whereas rocks along the hollow margin and exterior are more bladed in the axes ratio plot (Figure 8). By contrast, the rocks at Lonar are mostly compact, compact platy, compact bladed, compact elongated, platy, bladed, and elongate in the triangular form 


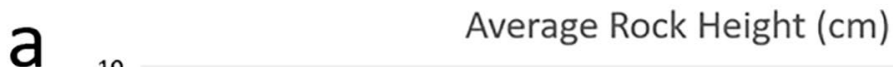

Average Rock Height (cm)

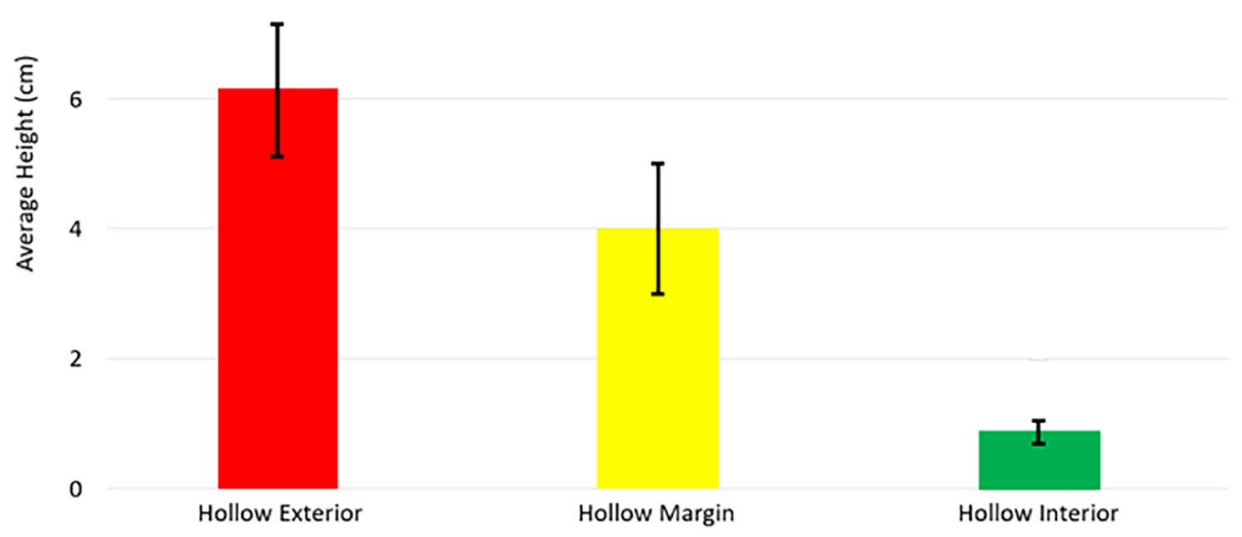

b

Average Rock Height for Rocks $>3 \mathrm{~cm}$

10

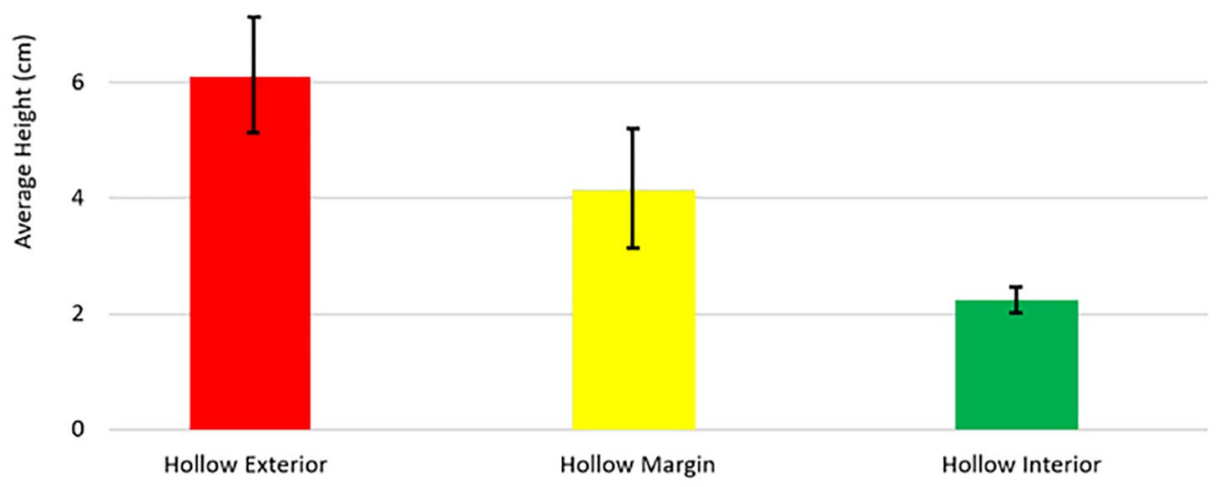

Figure 6. (a) Average height of rocks $>1 \mathrm{~cm}$ around the exterior ( 85 rocks), margin (68 rocks), and interior (1,850 rocks) of Homestead hollow are 6,4 , and $1 \mathrm{~cm}$, respectively. (b) Average height of rocks $>3 \mathrm{~cm}$ around the exterior ( 85 rocks), margin (65 rocks), and interior (504 rocks) of Homestead hollow are 6, 4, and $2 \mathrm{~cm}$, respectively. All rocks measured in the digital elevation model for both populations are included in the average and the standard error is indicated (standard deviation N/ square root of $\mathrm{N}$ ). There is a clear downward trend in rock height from the exterior to the interior and the minimal to nonexistent overlap (e.g., between the exterior and interior rock heights) for rocks $>1 \mathrm{~cm}$ and for rocks $>3 \mathrm{~cm}$ indicates the relative differences in rock height between the three areas are significant (especially between the exterior and interior) are not the result of higher image resolution and inclusion of smaller rocks for the interior. Because the rocks around the exterior and margin are more exposed based on their greater size and relative relief, their values are emphasized in consideration of the average amount of aeolian stripping that has occurred outside the hollow (Golombek, Warner et al., 2020; Grant et al., 2020; Warner, Grant, et al., 2020), and estimating the degree to which rocks remain embedded in the remnant ejecta.

factor plot (Figure 7), and ejecta rocks at Lonar plot as equant with lesser, but significant disc- and blade-shaped rocks in the axes ratio plot (Figure 8). Although Lonar is a relatively fresh impact crater where rocks have been subjected to more rapidly weathering versus the very degraded appearance of Homestead hollow, evaluation of basalt rock shapes from diverse geologic and weathering environments on Earth indicates there should be little effect on expected rocks shapes (Craddock \& Golombek, 2016). 


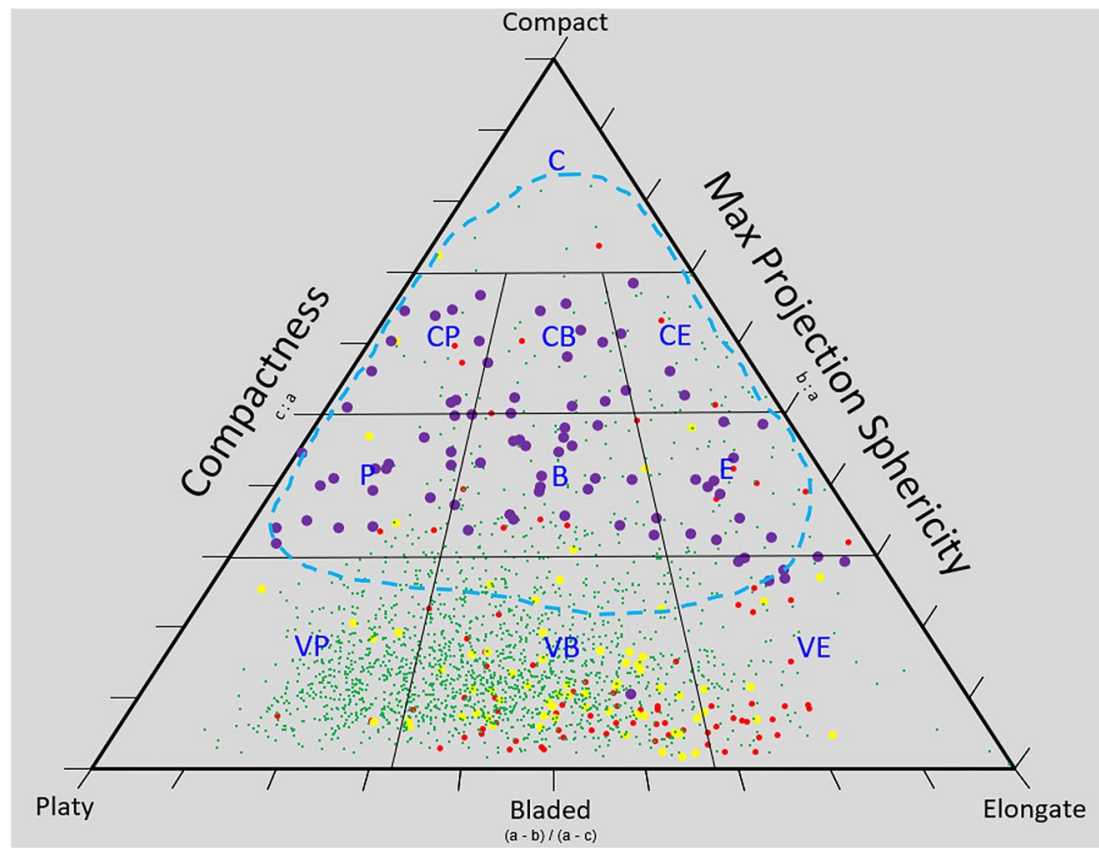

Figure 7. Form factor of basalt rocks in and around the InSight lander in Homestead hollow (each dot represents one rock). The shapes of InSight rocks within the hollow (green dots), along the hollow margin (yellow dots), and outside (red dots) the hollow are mostly platy, bladed, and elongate. Each purple dot (which correspond to a red dot) is the exterior rock shapes when $10 \mathrm{~cm}$ is added to the height to compensate for continued embedding in the remnant ejecta/regolith around the hollow. The purple dots indicate that rock shapes at InSight with $10 \mathrm{~cm}$ added to their height are similar to the shapes of fully exposed basalt rocks in a range of terrestrial environments including impact: rock shapes for the vast majority of the basalt rocks in ejecta at Lonar crater Kumar et al., 2014 are distributed within the blue dashed line that represents the data cloud that is similar to that for basalt rocks in other terrestrial environments (e.g., Craddock \& Golombek, 2016; Ehlmann et al., 2008). Field names with abbreviations are: (c) compact, CP-compact platy, CB-compact bladed, CE-compact elongated, P - platy, (b) bladed, (e) elongate, VP-very platy, VB-very bladed, and VE-very elongated. Note. that only the lowermost edge of field for Lonar rock shapes crosses into the VP, VB, and VE fields closer to the majority of rock shapes around InSight.

\section{Discussion}

We interpret that the greater rock heights on the hollow exterior are the result of greater rock exposure by aeolian stripping of the exterior versus interior infilling and rock burial, consistent with prior predictions that rocks around the hollow have been exposed by deflation (Golombek, Warner, et al., 2020; Grant et al., 2020; Warner, Grant, et al., 2020). Although normalizing rock heights by dividing the rock height by the average of the width and length yields overlap in the standard deviation for rocks in different zones, there is a general decreasing trend in height-to-width ratios from outside to inside the hollow (Table 1) that we interpret as consistent with increasing rock exposure across a range of rock sizes and shapes from inside to outside the hollow (as expected based on impact fragmentation) (Figure 6). The increasing percentage of rocks where height corresponds to the measured short axis from the exterior to margin to within the hollow is also consistent with our interpretation of the greater exposure of rocks on the exterior and near rim relative to increased rock burial in the interior.

We next explore whether aeolian stripping of the hollow exterior accompanied with downwind deposition in the hollow can account for hollow infilling (Golombek, Warner et al., 2020; Grant et al., 2020; Warner, Grant, et al., 2020). Although we report specific values for deflation and infilling that are based on multiple estimates for ejecta thickness and hollow volume, our intent is to evaluate whether reasonable amounts of deflation from the ejecta can account for infilling of the hollow versus exact prediction of deflation.

Expectations of few meter-scale rocks around and within the newly formed hollow implies that, if similar sized rocks are located on the floor of the hollow, they are less than the depth of fill. Continued, limited exposure of rocks inside the hollow (Golombek, Warner et al., 2020; Grant et al., 2020; Warner, Grant, et al., 2020) however, leads us to consider whether there are factors other than exterior stripping versus interior filling that are responsible for the difference in rock height between the exterior and interior of the hollow. 


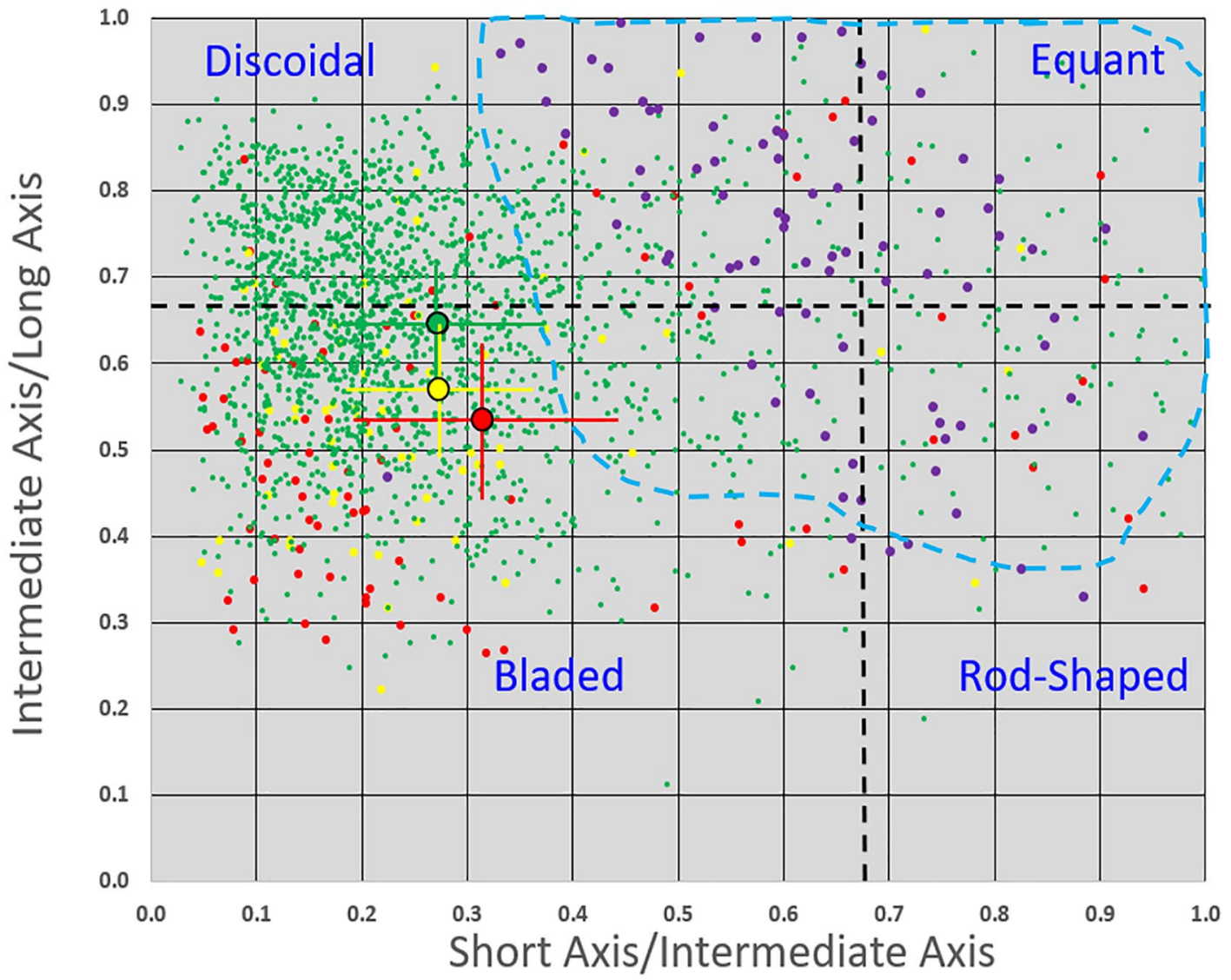

Figure 8. Plot of rock shape (each dot represents one rock) as defined by the ratio of the intermediate to short axis versus the short to intermediate axis after Zingg (1935). Most rocks inside the hollow (green dots) plot near the boundary between discoidal and bladed shapes, whereas rocks along the margin (yellow dots) and exterior to the hollow (red dots) are slightly more bladed in shape. The large red, yellow, and green dots mark the average and standard deviation of the rocks on the exterior, margin, and interior of the hollow, respectively, and highlight the general similarity in rock shape within and around the hollow. The blue dashed line encompasses the data cloud for basalt ejecta rocks at Lonar crater (Kumar et al., 2014) that is similar to that for basalt rocks in other terrestrial environments (e.g., Craddock \& Golombek, 2016; Ehlmann et al., 2008) and are mostly equant (34\%) with lesser, but significant disc-, rod- (28\%), and blade-shapes (10\%). Purple dots (one for each red dot) are rocks outside the hollow when it is assumed that the rocks remain embedded $10 \mathrm{~cm}$ in the surface and are generally similar to the shape of basalt rocks noted in terrestrial studies.

Hollow formation into a pre-existing impact-formed regolith ensures that rock sizes are well-mixed around and within the crater, in contrast to more recent studies that concluded the maximum size of interior rocks could be smaller than those on the near rim (Krishna \& Kumar, 2016; Lakshmi \& Kumar, 2020). The multiple impacts responsible for regolith formation further reduced rock sizes on the original hollow floor, thereby making their burial even more likely (Grant et al., 2020). Even if the hollow-forming impact occurred into bedrock instead of an impact-generated regolith, the maximum expected rock size is between 0.9-2.8 $\mathrm{m}$ (based on the relation between crater size and largest associated rock described in Moore, 1971) which is less than the expected depth of the crater and fill. As such, even if Homestead hollow formed in bedrock, any rock fragments located on the hollow floor would be buried. Hence, if the hollow is a primary crater, the rocks currently visible on the hollow fill do not extend to the buried floor but instead float on (in) and cap the infilling sediments (e.g., forming Rocky Field) as concluded in prior studies by Grant et al. (2020) and Warner, Grant et al. (2020).

We can compare observed and predicted heights of rocks located on the near-rim to the estimated amount of deflation there and relative to expected thickness and characteristics of the pristine ejecta. The approximate pristine ejecta thickness around the hollow can be estimated using:

$$
E_{t}=0.14 R_{t}^{0.74}\left(r / R_{t}\right)^{-2.5} \text { to }-3.5
$$

and 


$$
t_{e}=\mathrm{k}(r / R)^{-1.0}
$$

where in Equation 4 the thickness of the ejecta deposit $\left(E_{t}\right.$, measured in meters) is predicted based on measurements of explosion craters, Meteor Crater, and the lunar craters Copernicus and Imbrium, and can be related to the transient crater radius $R_{t}$ (where the transient crater diameter $\mathrm{D}_{t}$ is $0.84 \mathrm{D}$ ( $\mathrm{D}$ is the final diameter)) and radial distance $r$ from the crater rim, where $r>R_{t}$ (McGetchin et al., 1973). More recent work (Melosh, 1989) indicates that exponents between -2.5 and -3.5 may provide a more realistic range in estimates of the original ejecta thickness and we use this range in exponent values. By contrast, the thickness of the ejecta deposit $\left(t_{e}\right.$, measured in meters) in Equation 5 is based on measurements across nearly 100 Mars craters mostly in the northern hemisphere and is related to the ratio of the radial distance $r$ from the rim and the crater radius $\mathrm{R}$. The value of the constant $\mathrm{K}$ is 0.23 with a standard deviation of 0.47 (Garvin \& Frawley, 1998), leading us to calculate estimates based on values of $\mathrm{K}$ up to 0.7 to capture a range of possible values.

We use Equations 4 and 5 to estimate a range of realistic original ejecta thicknesses around Homestead hollow. From Equation 4 and the stated range of exponents, estimated ejecta thickness varies from $42-50 \mathrm{~cm}$ thick at the original rim to $26-35 \mathrm{~cm}$ at the current rim, 13-26 cm at three meters beyond the current rim, and only $1-3 \mathrm{~cm}$ at a range of 1D. From Equation 5, the stated range in $t_{e}$ is $23-70 \mathrm{~cm}$ at the original rim, $20-61 \mathrm{~cm}$ at the current $\mathrm{rim}, 16-50 \mathrm{~cm}$ at three meters beyond the current rim, and thins more gradually to a range of $1 \mathrm{D}$. There is significant overlap in the ejecta thicknesses predicted by Equations 4 and 5, but we emphasize values from Equation 4 because the Garvin \& Frawley (1998) study incorporates rampart and pedestal craters that are not good analogies for the original appearance of Homestead hollow based on examination of 1,000's of craters in the vicinity of the InSight lander (Sweeney et al., 2018; Warner, Grant et al., 2020). In summary, we believe the best estimate of the original ejecta thickness is $42-50 \mathrm{~cm}$ at the original rim down to $26-35 \mathrm{~cm}$ at the current rim, $13-26 \mathrm{~cm}$ out to three meters beyond the current rim tapering to $2-10 \mathrm{~cm} \mathrm{1D} \mathrm{(22-25} \mathrm{m,} \mathrm{original} \mathrm{diameter)} \mathrm{beyond} \mathrm{the} \mathrm{rim}$ of Homestead hollow. We also note that because the hollow was formed into pre-existing impact regolith, the properties of the materials beneath the rim and contributing to overall rim relief ( $\sim 50 \%$ of the total relief, see Shoemaker \& Kieffer, 1974; Melosh, 1989) should possess similar rock size and shape properties to the overlying ejecta. Hence, the original size and shape properties of the entire rim were fairly uniform, regardless of whether the crater was formed by a primary or secondary impact.

Based on published terrestrial comparisons (Grant \& Schultz, 1993; Kumar et al., 2014), we suggest the original ejecta around Homestead hollow graded from more clast-rich to more matrix-rich or even a matrix-supported deposit with increasing radial distance from the rim. Although thinner, ejecta further from the rim was likely characterized by fewer large rocks and more abundant fines, and may have supplied relatively more sediment (i.e., per unit volume) for transport due to a lesser abundance of lag or surface armoring rocks. Moreover, the multiple impact gardening of the regolith into which Homestead hollow formed would have produced abundant sand-sized material at the expense of fewer larger rocks in accordance with expectations from fragmentation during three impact events (M. Golombek, Charalambous et al., 2020; Golombek et al., 2018, 2021). Finally, the numerous rocks that are exposed around the margin and exterior of Homestead hollow implies the hollow-forming impact did not occur into pre-existing fines filling an older crater, in which case even more fines and fewer clasts would be expected (Grant et al., 2020). In any of these situations, variable numbers of relatively large (mostly 10's of $\mathrm{cm}$ with up to a few $1 \mathrm{~m}$ rocks) rocks would likely be present, but more common/numerous in the vicinity of the rim-crest.

We concur with the results of prior work (M. Golombek, Charalambous et al., 2020; Golombek et al., 2018, 2021) that the original ejecta around the hollow was characterized by rock sizes ranging from relatively few as large as a meter down to and including abundant sand-sized material, but with few rocks standing in significant relief. Moreover, the significant sand-sized material on the pristine surface was in disequilibrium with regional geomorphic thresholds (Grant et al., 2020, 2006; Warner, Grant, et al., 2020), susceptible to deflation, and winnowed from between rocks too large to be transported. The result was increasing exposure of the larger rocks that accumulated as an armoring lag over time (Grant et al., 2020). Because the original ejecta surface was susceptible to deflation, we next consider how differing amounts of aeolian deflation from the ejecta around the hollow compares to the estimated volume associated with aeolian fill inside the hollow. Sweeney et al. (2018) examined $\sim 100$ m-diameter craters in the InSight landing region using hillslope diffusion models over the timescales of the hollow lifetime (based on crater statistics) to replicate decreasing rim height over time related to back wasting and showed that these materials accounted for approximately $60 \%$ infilling of the crater. This indicated that the 
remainder of the depth-related degradation is accommodated by external filling agents (e.g., ejecta from later impacts) or aeolian fill) that contribute up to $40 \%$ of the total volume.

The volume of aeolian fill within the originally 22-25 m-diameter hollow can be constrained to first order using an original depth of $3.7 \mathrm{~m}$ (includes original rim height) that is now $0.3 \mathrm{~m}$ post-infilling (Warner, Grant, et al., 2020) and yields a total fill volume of $\sim 430-555 \mathrm{~m}^{3}$. If $60 \%$ of the infill is due to diffusional infilling from around the hollow and $40 \%$ is due to aeolian and other infilling, then the aeolian/other contribution to infilling is $\sim 172-222 \mathrm{~m}^{3}$. The small size and $3 \mathrm{~m}$ pristine depth of Homestead hollow (if a primary crater) relative to the typically larger ( $\sim 100$ m-diameter) craters examined be Sweeney et al. (2018) suggests the initial extent of steep slopes within the original crater capable of facilitating diffusional infilling ( $>38^{\circ}$, Sweeney et al., 2018) were limited and those surfaces would have been stabilized by increasing accumulation of talus and aeolian infill. Hence, we favor an increasingly important aeolian component to infilling as walls stabilized and diffusional processes waned, consistent with previous interpretations (Grant et al., 2020). To gain a sense of how the inventory of the original ejecta compares to the amount of fill, volumes represented by the minimum and maximum estimates of original ejecta thickness are 207 and $517 \mathrm{~m}^{3}$, and if $40 \%$ of the fill is eolian, 95 and $238 \mathrm{~m}^{3}$ of the minimum and maximum ejecta thickness volumes could have contributed to infilling, respectively. In some cases (for ejecta volumes corresponding to intermediate and thicker original ejecta thicknesses), therefore, deflation of the entire ejecta deposit could account for aeolian infilling if the entire deposit was susceptible to deflation (which is not the case given the number of $>1 \mathrm{~cm}$ rocks visible outside the current rim).

If the total $6 \mathrm{~cm}$ exposed rock relief or the $5 \mathrm{~cm}$ greater rock relief on the exterior of the hollow for the $>1 \mathrm{~cm}$ rock population represents uniform deflation to a range of 1D (approximate limit of the continuous ejecta, see Grant et al., 2008; Grant \& Schultz, 1993; Shoemaker \& Kieffer, 1974), leaving behind a lag of coarser fragments, it would represent $208 \mathrm{~m}^{3}$ and $175 \mathrm{~m}^{3}$ of sediment, respectively, in the range of what is necessary if $40 \%$ of the hollow fill is aeolian and all of the deflated sediment were transported into the hollow. If the $4 \mathrm{~cm}$ greater exposed rock relief on the exterior relative to the interior derived for the $>3 \mathrm{~cm}$ rock population represents uniform deflation to a range of $1 \mathrm{D}$, leaving behind a lag of coarser fragments, it would represent $156 \mathrm{~m}^{3}$ or somewhat less than necessary to account for 40 aeolian fill in the hollow even if all were transported into the hollow. Prevailing, reversing northwest-southeast winds (Banfield et al., 2020; Spiga et al., 2018) carrying along dust devils (Baker et al., 2020; Charalambous et al., 2020), however, would cause a significant fraction of transportable sediment southwest and northeast of the crater to be transported downrange and bypass the hollow. If half of the deflated sediment was blown back into the hollow by the prevailing winds, the volume contributing to infilling would be only $104 \mathrm{~m}^{3}$ and $88 \mathrm{~m}^{3}$, respectively, less than the lower end estimate required for $40 \%$ aeolian/other contribution to the total hollow fill.

Prior work (Golombek et al., 2006; Grant et al., 2006, 2008) demonstrates that the more exposed relief of a crater rim is more susceptible to, and experiences greater amounts of, deflation than lower relief, more distal surfaces (Golombek et al., 2006; Grant et al., 2006, 2008). Hence, we conclude that it is unlikely that the greater relief of near-rim rocks outside the hollow reflects a uniform amount of ejecta stripping from the entire deposit, but that greater deflation occurred in near rim areas. Further, we can use exposed relief on near-rim rocks to get an estimate of the aeolian erosion from the near rim ejecta based on prior work on the degradation history of the hollow (Golombek, Warner et al., 2020; Grant et al., 2020; Warner, Grant et al., 2020). The maximum relief of rocks around the hollow is just over $0.3 \mathrm{~m}$ as measured in the DEM and there are rare instances of rock relief as high as $0.4 \mathrm{~m}$ (First Rock, $\sim 20 \mathrm{~m}$ distance) and $0.5 \mathrm{~m}$ (Hanging Rock, $21 \mathrm{~m}$ distance) beyond the limit of the DEM (Golombek, Williams et al., 2020, 2021). Because Equations 4 and 5 predict less original ejecta at $\sim 20 \mathrm{~m}$ range, these two large rocks may not be in the hollow ejecta deposit, but protrude from the pre-impact surface. We conclude that the $0.3 \mathrm{~m}$ of relief on rocks along and in the few meters beyond the current rim provides a first-order estimate of deflation from the near-rim exterior of the hollow (allows for possibility that rocks could have partially protruded above the original ejecta surface). Accounting for increasing deflation of $0.4 \mathrm{~m}$ towards the original rim and decreasing deflation of $0.2 \mathrm{~m}$ outside $3 \mathrm{~m}$ beyond the current rim, and 0.1 and $0.05 \mathrm{~m}$ out to $1 \mathrm{R}$ and 1D, respectively, these values are also consistent with the predicted $0.7 \mathrm{~m}$ (locally up to $1 \mathrm{~m}$ ) initial versus current 0.3 rim relief. This model yields deflated sediment volumes of 354 or $177 \mathrm{~m}^{3}$ if $50 \%$ was blown back into the crater. This is within, but close to the lower end of the range of estimates for the aeolian component of fill in the hollow and indicates that predictions of deflation based on exposed rock relief can equate to a $40 \%$ aeolian component to hollow infilling and that significant contributions from later arriving ejecta are not required. 
As a reality check, our estimate of deflated ejecta and associated volume transported downwind into the crater based on current exposed rock relief is intermediate to the minimum and maximum estimated volumes of original ejecta. We further conclude that the near-surface around the hollow and beneath the ejecta should have similar properties to the ejecta based on the impact-gardened origin of the target regolith and was therefore similarly susceptible to deflation. Hence, we view rock relief as a realistic proxy for deflation for even the minimum original volume of ejecta or if the hollow is a secondary crater (which we conclude is unlikely for reasons already stated) because underlying regolith would have provided an additional, potential inventory of sediments for erosion and transport (and the required volume of fill would have been less in the unlikely event the hollow was a shallower secondary crater).

Rock shapes at Homestead hollow provide another check on whether deflation estimates based on exterior rock relief are realistic. In contrast to the expectation of mostly compact, compact platy, compact bladed, compact elongated, platy, bladed, and elongate rocks (Figure 7) or mostly equant ( $\sim 1 / 3$ of the total) with lesser, disc- and blade-shaped rocks (Figure 8) based on rock shapes at Lonar crater and elsewhere (Craddock \& Golombek, 2016; Ehlmann et al., 2008; Kumar et al., 2014) there is a preponderance of platy, bladed, and elongate rocks at InSight. We also note that the average values for maximum projection sphericity of 0.35 and deviation from compactness of just under 0.2 at Homestead hollow, are well below the average of 0.72 and 0.53 , respectively, of rocks measured at Lonar crater. Interestingly, the form factor averages $0.52-0.57$ for rocks around and outside of the hollow and is comparable to the average of 0.56 observed at Lonar. We next explore whether these differences/similarity may hold clues to understanding differences in observed versus expected rock shapes at InSight.

Possible reasons for apparent differences in rock shape parameters at InSight include: (1) error in measurements made in the direction viewed from the lander if the rock profile precludes accurate measure of dimensions; and (or) (2) the partially buried nature of the InSight rocks (especially inside the hollow) causes the axis associated with rock height to be underestimated. The former can be shown to have a minimal effect because the rock axis radial to the lander is not systematically smaller in the DEM coverage than the axis facing the lander and the average shape parameters of rocks on the exterior rim versus margin versus interior do not show systematic changes (Figure 8).

For the second possibility, the embayed appearance of the base of many of the exterior near-rim rocks (that precludes visual confirmation of complete rock height), and apparently nearly completely buried appearance of rocks within the hollow (based on some rocks visible only as nearly flat surfaces that barely protrude above the fill), suggests that the true rock heights are underestimated. The predominance of rock height as the smallest rock axis, provides support for this statement. For example, height acts as the short axis for a large majority (78\%) of the rocks on the near-rim and suggests that underestimation of rock height is skewing the shape analyses. Equations 1 and 2 emphasize the smallest rock axis in the numerator that can directly reduce estimated values of maximum projection sphericity and deviation from compactness. By contrast, the form factor includes the smallest axis of each rock as a difference in the denominator that dilutes the impact on the calculated values. We interpret these factors as an indication that rocks remain partially embedded or buried.

Assuming that basalt rock shapes at InSight are similar to basalt rock shapes on Earth, we recalculated shape parameters and plots after addition of relief to rocks on the near-rim to account for their partially embedded appearance. We focused on rocks around the exterior of the hollow because they are the best exposed (based on greater rock relief and 13\% and 19\% lesser percentage of measured height as the short rock axis as compared to rocks on the margin and interior, respectively) and made comparisons to the maximum estimated thickness of the original ejecta deposit.

We find that the addition of $10 \mathrm{~cm}$ to the height of each rock on the exterior of the hollow to account for continued partial embedding results in the best match between rock shapes at Insight and around Lonar crater (Figures 7 and 8). These recalculated shape parameters yield revised average values for maximum projection sphericity of 0.65 (0.09 standard deviation, range between 0.29 and 0.85$)$, compactness is 0.45 ( 0.11 standard deviation, range between 0.11 and 0.68 ), and form factor is 0.49 ( 0.26 standard deviation, range 0.01 and 0.95 ), all much closer to the corresponding values of $0.72,0.53$, and 0.56 for ejecta rocks at Lonar crater, respectively. The resultant recalculated values for exterior rocks plus $10 \mathrm{~cm}$ are shown in the Figure 7 TRI-PLOT (Sneed \& Folk, 1958) and shows that the overwhelming majority superposes the range of data points for ejecta rocks at Lonar crater. Moreover, comparison between our estimated 30-50 cm original thickness of pristine ejecta within $6 \mathrm{~m}$ of the 
original hollow rim (the outer $\sim 3 \mathrm{~m}$ is covered by the DEM) and the $\sim 30 \mathrm{~cm}$ exposed relief on exterior near-rim rocks indicates that $10 \mathrm{~cm}$ average embedding is reasonable and responsible for the embayed appearance of most rocks. If correct, our interpretation indicates rock shapes at InSight are comparable to those expected from basalt rocks shapes on Earth (e.g., Craddock \& Golombek, 2016; Ehlmann et al., 2008; Kumar et al., 2014). Hence, our model of $\sim 30 \mathrm{~cm}$ deflation at the current hollow rim (decreasing outwards, increasing inwards) is consistent with observed versus expected rock shapes and deflation estimated using observed exterior rock height relative to original ejecta thickness and the aeolian component of hollow infilling.

The current expression of rocks inside the hollow provides additional clues regarding the degradation history. Based on previous work on the timeline of hollow degradation (Grant et al., 2020; Warner, Grant, et al., 2020), initially high rates of rim stripping and infilling during the first 0.05-0.1 Ga after hollow formation quickly slowed as surrounding ejecta became armored by a coarse lag that precluded aeolian transport. This prior work has shown that the degradation rate following early degradation was only $10^{-4} \mathrm{~m} / \mathrm{Myr}$ and characterized most of the 0.4-0.7 Ga history of the hollow (Sweeney et al., 2018; Warner, Grant, et al., 2020).

Rocks inside the hollow (where proximity to the lander enables accurate measure of rocks to less than $1 \mathrm{~cm}$, see Golombek et al., 2021) average $\sim 1 \mathrm{~cm}$ in height, only $1 \%$ are greater than $10 \mathrm{~cm}$ tall, and prior work indicates most or all are distal ejecta delivered during nearby impacts (Grant et al., 2020). Even limited, continued partial exposure of the rocks forming Rocky Field (Figures 1 and 2) requires they were emplaced near the end or just after higher degradation during up to the first $0.1 \mathrm{Ga}$ of hollow history (Grant et al., 2020; Sweeney et al., 2018; Warner, Grant, et al., 2020). Although the actual size of the interior rocks is uncertain due to partial embayment that precludes measure of the entire height, the ratio of their height to average width, uniform expression above the fill, origin as distal ejecta from a later impact (Grant et al., 2020), and comparison to the average size of relatively more exposed rocks around the rim suggests most are less than $10 \mathrm{~cm}$ tall. The $10^{-4} \mathrm{~m} / \mathrm{Myr}$ degradation rate over the $0.3-0.6 \mathrm{Ga}$ after early, higher degradation rates equates to $\sim 3-6 \mathrm{~cm}$ of infilling since the ejecta rocks forming Rocky Field were emplaced. Hence, the small size and continued, albeit limited, exposure of the rocks in Rocky Field and other interior rocks is consistent with prior estimates of very slow degradation over most of hollow history.

Our interpretations are consistent with the results of prior work related to the modification history of the hollow. If correct, they represent a new tool for constraining hollow degradation: the exposed rock relief around the near-rim relative to expectations of original ejecta thickness coupled with consideration of observed versus expected rock shapes are consistent with deflation of $30 \mathrm{~cm}$ at the current rim (and up to $40 \mathrm{~cm}$ at the original rim), decreasing with greater range. Moreover, the sediment volume represented by that amount of deflation during prevailing winds is a reasonable match to the expected $40 \%$ volume of aeolian contributions to hollow infilling. In our model, deflation from the upwind sides of the hollow and subsequent downwind deposition in the hollow can account for most or all of the aeolian infilling and that there are only minimal additional infilling contributions associated with aeolian transport from ejecta or by direct delivery of ejecta from around later forming craters. Instead, the inventory of deflated ejecta sediment bypassing the hollow likely contributed to aeolian bedforms observed in the vicinity of the landing site (e.g., Golombek, Warner, et al., 2020; Warner, Grant, et al., 2020) and (or) regolith formation.

Minimal infilling via transport of deflated fines from ejecta around younger nearby craters or by direct delivery of ejecta from around nearby, later impacts is also consistent with early, more rapid infilling followed by very slow degradation over the bulk of hollow history as expressed in the continued, limited exposure of embayed rocks comprising Rocky Field and elsewhere across the hollow interior. Small rocks forming Rocky Field were likely emplaced during the first $\sim 0.1 \mathrm{Ga}$ after the hollow formed (Grant et al., 2020; Warner, Grant, et al., 2020) on a surface close to what is observed in the hollow today. And their continued exposure is inconsistent with more significant infilling associated with aeolian transport from ejecta around later occurring impacts.

\section{Summary}

The rocks heights and shapes around and within Homestead hollow provide evidence regarding degradation over time that is realistic when compared to contributions from various processes inferred from prior studies (Golombek, Warner, et al., 2020; Grant et al., 2020; Warner, Grant, et al., 2020). We find that decreasing average rock height, decreasing largest (exposed) rock size, and increasing percentage of rocks where height is the short 
axis, characterize rocks from outside to within the hollow. Our observations, coupled with estimation of likely original ejecta properties and thickness, support deflation of $0.3 \mathrm{~m}$ from the ejecta at the current rim, up to $40 \mathrm{~cm}$ at the original rim, and decreasing amounts beyond the current rim. If $50 \%$ of the deflated sediment is transported into the hollow by prevailing wind, the resultant contribution to infilling is close to the previously predicted $40 \%$ non-diffusional contribution to infilling (Sweeney et al., 2018; Warner, Grant, et al., 2020). Moreover, differences between observed versus expected (e.g., Craddock \& Golombek, 2016; Ehlmann et al., 2008; Kumar et al., 2014) rock shapes on the near-rim exterior of the hollow largely disappear when an average of $10 \mathrm{~cm}$ is added to rock heights in this zone to account for embayment/partial embedding of rock bases in the remnant ejecta and (or) underlying regolith. Finally, we interpret continued exposure of ejecta rocks within the hollow (e.g., Rocky Field) as being consistent with prior estimates of only $10^{-4} \mathrm{~m} / \mathrm{Myr}$ degradation over the past $0.3-0.6 \mathrm{Ga}$ history of the hollow (Sweeney et al., 2018; Warner, Grant, et al., 2020). Our results suggest that a significant fraction of deflated sediments bypassed the hollow via prevailing winds and likely become trapped by local topography and contributing to nearby bedforms and (or) regolith. These sediments do not appear to make appreciable $(>10 \mathrm{~cm}$ thick) contribution to most older impact structures located downwind. The latter point and minimal infilling by direct arrival of ejecta during later impacts may reflect the typically long period between random impacts at a given point as compared to the duration of the early higher rate of crater degradation that results in most modification and distribution of fines into stable, long-term reservoirs (i.e., the hollow interior and nearby bedforms).

Because regolith-mantled volcanic surfaces of intermediate to young age (i.e., Hesperian to Amazonian) are widespread on Mars (Tanaka et al., 2014), our results of evaluating rock heights and shape around small impact craters like Homestead Hollow can be an important tool for understanding local degradation history on Mars.

\section{Data Availability Statement}

All data used in the paper is freely accessible at the link provided below in the data availability statement that follows. This is InSight Contribution Number 229. Data used in analyses of rocks at the InSight lander and described in the paper are included in three Microsoft 365 Excel files (and associated readme explanation Word file) and ArcGIS shape files (and associated readme explanation Word file, and orthophoto and DEM) that can be freely accessed and downloaded for viewing at Smithsonian. figshare: https://doi.org/10.25573/data.15121554.

\section{References}

Acknowledgments

We thank the Jet Propulsion Laboratory, Lockheed Martin Space Systems, CNES, and other partner institutions that built and operate the InSight lander. A portion of the work was supported by the InSight Project at the Jet Propulsion Laboratory, California Institute of Technology, and under grants $80 \mathrm{NSSC} 18 \mathrm{~K} 1625$ to J. Grant (includes S. Wilson and C. Weitz) and 80NSSC18K1624 to N. Warner from the National Aeronautics and Space Administration. This is InSight Contribution Number 229.
Abarca, H., Deen, R., Hollins, G., Zamani, P., Maki, J., Tinio, A., et al. (2019). Image and data processing for InSight lander operations and science. Space Science Reviews, 215(2), 22. https://doi.org/10.1007/s11214-019-0587-9

Baker, M. M., Newman, C., Charalambous, C., Golombek, M. P., Spiga, A., Banfield, D., et al. (2020). Vortex-dominated aeolian activity at InSight's landing site, Part 2: Threshold conditions and model comparisons. Journal of Geophysical Research: Planets. https://doi. org/10.1029/2020JE006514

Banerdt, W. B., Smrekar, S. E., Banfield, D., Giardini, D., Golombek, M., Johnson, C. L., et al. (2020). Early results from the InSight mission: Mission overview and global seismic activity. Nature Geoscience, 13, 183-189. https://doi.org/10.1038/s41561-020-0544-y

Banfield, D., Spiga, A., Newman, C., Forget, F., Lemmon, M., Lorenz, R., et al. (2020). The atmosphere of Mars as observed by InSight. Nature Geoscience, 13, 190-198. https://doi.org/10.1038/s41561-020-0534-0

Bonneau, D. A., Hutchinson, D. J., DiFrancesco, P.-M., Coombs, M., \& Sala, Z. (2019). Three-dimensional rockfall shape back analysis: Methods and implications. Natural Hazards and Earth System Sciences, 19, 2745-2765. https://doi.org/10.5194/nhess-19-2745-2019

Brown, W. K. (1989). A theory of sequential fragmentation and its astronomical applications. Journal of Astrophysics \& Astronomy, 10, 89-112. https://doi.org/10.1007/bf02714980

Charalambous, C., McClean, J., Baker, M. M., Pike, W. T., Golombek, M. P., Lemmon, M. T., et al. (2020). Vortex-dominated aeolian activity at InSight's landing site: Multi-instrument observations, analysis and implications. Journal of Geophysical Research: Planets. https://doi. org/10.1029/2020JE006757

Corey, A. T. (1949). Influence of shape on fall velocity of sand grains (p. 102). Unpublished M. Sc. Thesis, Colorado A\&M College.

Craddock, R. A., \& Golombek, M. P. (2016). Characteristics of terrestrial basaltic rock populations: Implications for Mars lander and rover science and safety. Icarus, 274, 50-72. https://doi.org/10.1016/j.icarus.2016.02.042

Daubar, I. J., Golombek, M. P., McEwen, A. S., Tornabene, L. L., Calef, F. J., III, Fergason, R., et al. (2016). Depth-diameter ratio of Corinto secondary craters, 47 th lunar and planetary science.

Ehlmann, B. L., Viles, H. A., \& Bourke, M. C. (2008). Quantitative morphologic analysis of boulder shape and surface texture to infer environmental history: A case study of rock breakdown at the Ephrata fan, Channeled scabland, Washington. Journal of Geophysical Research: Earth Surface, 113, F02012. https://doi.org/10.1029/2007JF000872

Garvin, J. B., \& Frawley, J. J. (1998). Geometric properties of Martian impact craters: Preliminary results from the Mars orbiter laser altimeter. Geophysical Research Letters, 25, 4405-4408. https://doi.org/10.1029/1998g1900177

Garvin, J. B., Mouginis-Mark, P. J., \& Head, J. W. (1981). Characterization of rock populations on planetary surfaces: Techniques and a preliminary analysis of Mars and Venus. The Moon and the Planets, 24, 355-387. https://doi.org/10.1007/bf00897109

Golombek, M., Charalambous, C., Pike, W. T., \& Sullivan, R. (2020). The origin of sand and dust on Mars: Evidence from the InSight landing site, 51st Lunar and Planetary Science. 
Golombek, M., Kipp, D., Warner, N., Daubar, I. J., Fergason, R., Kirk, R. L., et al. (2017). Selection of the InSight landing site. Space Science Reviews, 211(1-4), 5-95. https://doi.org/10.1007/s11214-016-0321-9

Golombek, M., Williams, N., Warner, N. H., Parker, T., Williams, M. G., Daubar, I., et al. (2020). Location and setting of the Mars InSight lander, instruments, and landing site. Earth and Space Science, 7, e2020EA001248. https://doi.org/10.1029/2020EA001248

Golombek, M. P., Charalambous, C., Pike, W. T., \& Sullivan, R. (2018). The origin of sand on Mars, 49th Lunar and Planetary Science.

Golombek, M. P., Grant, J. A., Crumpler, L. S., Greeley, R., Arvidson, R. E., Bell, J. F., III, et al. (2006). Erosion rates at the Mars Exploration Rover landing sites and long-term climate change on Mars. Journal of Geophysical Research: Planets, 111. https://doi.org/10.1029/2006JE002754

Golombek, M. P., Grott, M., Kargl, G., Andrade, J., Marshall, J., Warner, N., et al. (2018). Geology and physical properties investigations by the InSight lander. Space Science Reviews, 214, 84. https://doi.org/10.1007/s11214-018-0512-7

Golombek, M. P., Kass, D., Williams, N., Warner, N., Daubar, I., Piqueux, S., et al. (2020). Assessment of InSight landing site predictions. Journal of Geophysical Research: Planets, 125, e2020JE006502. https://doi.org/10.1029/2020JE006502

Golombek, M. P., Trussell, A., Williams, N., Charalambous, C., Abarca, H., Warner, N. H., et al. (2021). Rock Size-frequency distribution of the InSight landing site, Mars. Earth and Space Science. https://doi.org/10.1029/2021EA001959

Golombek, M. P., Warner, N. H., Grant, J. A., Hauber, E., Ansan, V., Weitz, C. M., et al. (2020i). Geology of the InSight landing site on Mars. Nature Communications, 11. https://doi.org/10.1038/s41467-020-14679-1

Graham, D. J., \& Midgley, N. G. (2000). Graphical representation of particle shape using triangular diagrams: An Excel spreadsheet method. Earth Surface Processes and Landforms, 25(13), 1473-1477. https://doi.org/10.1002/1096-9837(200012)25:13<1473::aid-esp158>3.0.co;2-c

Grant, J. A., Arvidson, R. E., Bell, J. F., III, Cabrol, N. A., Carr, M. H., Christensen, P. R., et al. (2004). Surficial deposits at Gusev crater along spirit rover traverses. Science, 305, 807-810. https://doi.org/10.1126/science.1099849

Grant, J. A., Arvidson, R. E., Crumpler, L. S., Golombek, M. P., Hahn, B., Haldemann, A. F. C., et al. (2006). Crater gradation in Gusev crater and Meridiani planum, Mars. Journal of Geophysical Research, 111. https://doi.org/10.1029/2005JE002465

Grant, J. A., \& Schultz, P. H. (1993). Erosion of ejecta at Meteor Crater, Arizona. Journal of Geophysical Research, 98(15), 033-15. https://doi. org/10.1029/93je01580

Grant, J. A., Warner, N. H., Weitz, C. M., Golombek, M. P., Wilson, S. A., Baker, M., et al. (2020). Degradation of Homestead hollow at the InSight landing site based on the distribution and properties of local deposits. Journal of Geophysical Research: Planets, 125. https://doi. org/10.1029/2019JE006350

Grant, J. A., Wilson, S. A., Cohen, B. A., Golombek, M. P., Geissler, P. E., Sullivan, R. J., et al. (2008). Degradational modification of victoria crater, Mars. Journal of Geophysical Research, 113, E11010. https://doi.org/10.1029/2008JE003155

Grant, J. A., Wilson, S. A., Golombek, M. P., Trussell, A., Warner, N. H., Williams, N., et al. (2021). Data Repository for rock dimension data and related plots for fragments around the InSight lander, Mars. Smithsonian figshare. https://doi.org/10.25573/data.15121554

Head, J. N., Melosh, H. J., \& Ivanov, B. A. (2002). Martian meteorite launch:High-speed ejecta from small craters. Science, $298,1752-1756$. https://doi.org/10.1126/science.1077483

Krishna, N., \& Kumar, P. S. (2016). Impact spallation processes on the Moon: A case study from the size and shape analysis of boulders and secondary craters of Censorinus crater. Icarus, 264, 274-299. https://doi.org/10.1016/j.icarus.2015.09.033

Krumbein, W. C. (1941). Measurement and geologic significance of shape and roundness of sedimentary particles. Journal of Sedimentary Petrology, 11, 64-72.

Kumar, S. P., Prasanna Lakshmi, K. J., Krishna, N., Menon, R., Sruthi, U., \& Keerthi, V. (2014). Impact fragmentation of Lonar Crater, India: Implications for impact cratering processes in basalt. Journal of Geophysical Research: Planets, 119, 2029-2059. https://doi. org/10.1002/2013JE004543

Lakshmi, K. J. P., \& Kumar, P. S. (2020). Physical properties of basalt ejecta boulders at Lonar crater, India: Insights into the target heterogeneity and impact spallation processes in basalt with application to Mars. Journal of Geophysical Research: Planets, 125, e2020JE006593. https:// doi.org/10.1029/2020JE006593

Maki, J., Golombek, M. P., Deen, R., Abarca, H., Sorice, C., Goodsall, T., et al. (2018). The color cameras on the Insight lander. Space Science Reviews, 214, 105. https://doi.org/10.1007/s11214-018-0536-Z

McGetchin, T. R., Settle, M., \& Head, J. W. (1973). Radial thickness variation in impact crater ejecta: Implications for lunar basin deposits. Earth and Planetary Science Letters, 20, 226-236. https://doi.org/10.1016/0012-821x(73)90162-3

Melosh, H. J. (1984). Impact ejection, spallation, and the origin of meteorites. Icarus, 59, 234-260. https://doi.org/10.1016/0019-1035(84)90026-5

Melosh, H. J. (1989). Impact cratering (p. 245). Oxford University Press.

Moore, H. J. (1971). Large blocks around lunar craters. In Analysis of Apollo 10 photography and visual observations. NASA Special Publication SP-232, 26-27.

Pan, L., Quantin-Nataf, Q., Tauzin, B., Michaut, C., Golombek, M. P., Lognonné, P., et al. (2020). Crust stratigraphy and heterogeneities of the first kilometers at the dichotomy boundary in western Elysium Planitia and implications for InSight lander. Icarus, 338. https://doi. org/10.1016/j.icarus.2019.113511

Pike, R. J., \& Wilhelms, D. E. (1978). Secondary-impact craters on the Moon: Topographic form and geologic process, 9th Lunar and Planetary Science.

Schroder, S. E., Carsemtu, U., Hauber, E., Schulzeck, F., Raymond, C. A., \& Russell, C. T. (2020). The boulder population of asteroid Vesta 4: Size-Frequency distribution and survival time. Earth and Space Science, 8, e2019EA000941. https://doi.org/10.1029/2019EA000941

Schroder, S. E., Carsenty, U., Hauber, E., Raymond, C. A., \& Russell, C. T. (2021). The brittle boulders of dwarf planet Ceres. The Planetary Science Journal, 2, 111. 15pp. https://doi.org/10.3847/PSJ/abfe66

Shoemaker, E. M., \& Kieffer, S. E. (1974). Guidebook to the geology of Meteor Crater, Arizona (Vol. 17, p. 66). Pub.Arizona State University Center for Meteorite Studies.

Sneed, E. D., \& Folk, R. L. (1958). Pebbles in the lower Colorado river, Texas: A study in particle morphogenesis. The Journal of Geology, 66(2), 114-150. https://doi.org/10.1086/626490

Spiga, A., Banfield, D., Teanby, N. A., Forget, F., Lucas, A., Kenda, B., et al. (2018). Atmospheric science with Insight. Space Science Reviews, 214, 109. https://doi.org/10.1007/s11214-018-0543-0

Sweeney, J., Warner, N. H., Ganti, V., Golombek, M. P., Lamb, M. P., Fergason, R., \& Kirk, R. (2018). Degradation of 100-m-scale rocky ejecta craters at the InSight landing site on Mars and implications for surface processes and erosion rates in the Hesperian and Amazonian. Journal of Geophysical Research: Planets, 123, 2732. https://doi.org/10.1029/2018JE005618

Tanaka, K., Skinner, J. A., Jr, Dohm, J. M., Irwin, R. P., III, Kolb, E. J., Fortezzo, C. M., et al. (2014). Geologic map of Mars (p. 3292). United States Geological Survey Science Investigations Mappemonde. 
Warner, N. H., Golombek, M. P., Sweeney, J., Fergason, R., Kirk, R., \& Schwartz, C. (2017). Near surface stratigraphy and regolith production in southwestern Elysium Planitia, Mars: Implications for Hesperian-Amazonian terrains and the InSight lander mission. Space Science Reviews, 211, 147. https://doi.org/10.1007/s11214-017-0352-x

Warner, N. H., Grant, J. A., Wilson, S. A., Golombek, M. P., DeMott, A., Charalambous, C., et al. (2020). An impact crater origin for the Insight landing site at Homestead Hollow: Implications for near surface stratigraphy, surface processes, and erosion rates. Journal of Geophysical Research: Planets, 125. https://doi.org/10.1029/2019je006333

Warner, N. H., Schuyler, A. J., Rogers, A. D., Golombek, M. P., Grant, J. A., \& Wilson, S. A. (2020). Crater morphometry on the mafic floor unit at Jezero crater, Mars: Comparisons to a known basaltic lava plain at the InSight landing site. Geophysical Research Letters, 47 . https:// doi.org/10.1029/2020GL089607

Watters, W. A., Geiger, L. M., Fendrock, M., Gibson, R., \& Hundal, C. B. (2017). The role of strength defects in shaping impact crater planforms. Icarus, 286, 15-34. https://doi.org/10.1016/j.icarus.2016.12.024

Williams, N., Golombek, M. P., Warner, N. H., Daubar, I. J., Hausmann, R. B., Hauber, E., et al. (2019). Surface alteration from landing InSight on Mars and its implications for shallow regolith structure, 50th Lunar and Planetary Science.

Yingst, R. A., Crumpler, L., Farrand, W. H., \& de Souza, P. (2010). Constraints on the geologic history of "Home Plate" materials provided by clast morphology and texture. Journal of Geophysical Research, 115, E00F13. https://doi.org/10.1029/2010JE003668

Yingst, R. A., Crumpler, L., Farrand, W. H., Li, R., Cabrol, N. A., \& Neakrase, L. D. (2008). Morphology and texture of particles along the Spirit rover traverse from sol 450 to sol 745. Journal of Geophysical Research, 113, E12S41. https://doi.org/10.1029/2008JE003179

Yingst, R. A., Haldemann, A. F. C., Biedermann, K. L., \& Monhead, A. M. (2007). Quantitative morphology of rocks at the Mars Pathfinder landing site. Journal of Geophysical Research, 112, E06002. https://doi.org/10.1029/2005JE002582

Yingst, R. A., Kah, L. C., Palucis, M., Williams, R. M. E., Garvin, J., Bridges, J. C., et al. (2013). Characteristics of pebble- and cobble-sized clasts along the Curiosity rover traverse from Bradbury Landing to Rocknest. Journal of Geophysical Research: Planets, 118, 2361-2380. https://doi.org/10.1002/2013JE004435

Zingg, T. (1935). Beitrage Zur schotteranalyse. Schweizerische Mineralogische und Petrographische Mitteilungen, 15, 39-14. 